\title{
MYTH AND REALITY OF FLAT TAX REFORM: MICRO ESTIMATES OF TAX EVASION RESPONSE AND WELFARE EFFECTS IN RUSSIA
}

\author{
Yuriy Gorodnichenko \\ Jorge Martinez-Vazquez \\ Klara Sabirianova Peter \\ Working Paper 13719 \\ http://www.nber.org/papers/w13719
}

\author{
NATIONAL BUREAU OF ECONOMIC RESEARCH \\ 1050 Massachusetts Avenue \\ Cambridge, MA 02138 \\ January 2008
}

The authors would like to thank Alan Auerbach, Raj Chetty, John Earle, Brian Erard, Caroline Hoxby, Patrick Kline, Emmanuel Saez, and seminar participants at Stanford University, the Upjohn Institute for Employment Research, and the Kyiv School of Economics and the participants at the AYSPS conference "Tax Compliance and Tax Evasion" in Atlanta, GA for useful comments. We are also thankful to Ben Miller for research assistance. Sabirianova Peter acknowledges the research support from the National Council for Eurasian and East European Research and research initiation grant from Georgia State University. The views expressed herein are those of the author(s) and do not necessarily reflect the views of the National Bureau of Economic Research.

NBER working papers are circulated for discussion and comment purposes. They have not been peerreviewed or been subject to the review by the NBER Board of Directors that accompanies official NBER publications.

(C) 2008 by Yuriy Gorodnichenko, Jorge Martinez-Vazquez, and Klara Sabirianova Peter. All rights reserved. Short sections of text, not to exceed two paragraphs, may be quoted without explicit permission provided that full credit, including $\odot$ notice, is given to the source. 
Myth and Reality of Flat Tax Reform: Micro Estimates of Tax Evasion Response and Welfare Effects in Russia

Yuriy Gorodnichenko, Jorge Martinez-Vazquez, and Klara Sabirianova Peter

NBER Working Paper No. 13719

January 2008

JEL No. D73,H21,H24,H26,J3,O1,P2

\begin{abstract}
Using micro-level data, we examine the effects of Russia's 2001 flat rate income tax reform on consumption, income, and tax evasion. We use the gap between household expenditures and reported earnings as a proxy for tax evasion with data from a household panel for 1998-2004. Utilizing difference-in-difference and regression-discontinuity-type approaches, we find that large and significant changes in tax evasion following the flat tax reform are associated with changes in voluntary compliance and cannot be explained by changes in tax enforcement policies. We also find the productivity response of taxpayers to the flat tax reform is small relative to the tax evasion response. Finally, we develop a feasible framework to assess the deadweight loss from personal income tax in the presence of tax evasion based on the consumption response to tax changes. We show that because of the strong tax evasion response the efficiency gain from the Russian flat tax reform is at least $30 \%$ smaller than the gain implied by conventional approaches.
\end{abstract}

Yuriy Gorodnichenko

Department of Economics

549 Evans Hall \#3880

University of California, Berkeley

Berkeley, CA 94720-3880

and NBER

ygorodni@econ.berkeley.edu

Jorge Martinez-Vazquez

Georgia State University

Andrew Young School of Policy Studies

14 Marietta Street, Suite 557

Atlanta, Georgia 30303-3083

jorgemartinez@gsu.edu
Klara Sabirianova Peter

Andrew Young School of Policy Studies

Georgia State University

P.O. Box 3992, Atlanta, GA 30302-3992

kpeter@gsu.edu 


\section{Introduction}

Tax evasion is a pervasive worldwide phenomenon. It is widely believed that high personal income tax (PIT) rates are partially responsible for high levels of tax evasion everywhere, especially in emerging markets. High personal income tax rates are also often associated with negative effects on economic activity. This study offers a broadly applicable method to assess the impact of changes in personal income tax on the level of tax evasion and productivity by using consumption and income data from household surveys. ${ }^{1}$ The study also develops a framework to assess the welfare costs of distortionary personal income taxes in the presence of tax evasion based on the consumption response to tax changes. We exploit unique features of the well known Russian flat rate tax reform of 2001 to identify the effect of changes in the personal income tax on tax evasion, productivity, and welfare. Using a variety of statistical methods, robustness checks, and the richness of the data in the Russian Longitudinal Monitoring Survey (RLMS), we conclude: $i$ ) that the tax evasion in response to the tax change was large, but, $i i$ ) that the productivity response was relatively weak and, hence, iii) that the welfare gains from cutting tax rates were considerably smaller than was thought before.

In January 2001, Russia introduced a fairly dramatic reform of its personal income tax when it became the first large economy to adopt a flat rate personal income tax. The Tax Code of 2001 replaced the previous conventional progressive rate structure with a flat tax rate of 13 percent (Figure 1). ${ }^{2}$ Over the next year, the Russian economy grew at almost 5 percent in real terms, while revenues from the personal income tax increased by over 25 percent in real terms (Table 1). Advocates of the flat tax largely credit Russia's flat tax reform with this dramatic turn in revenue

\footnotetext{
${ }^{1}$ In our definition, the productivity response is the behavioral response that changes the amount of total resources available to households for consumption, while the tax evasion response involves shifting resources from one account ('non-reported income') to another ('reported income') without affecting the amount of total resources. The key difference between the responses is that the first response increases the size of the 'pie' available in the economy while the second response simply redistributes the 'pie' into different accounts. Our productivity response is known by other names in the literature: earned income response, real response, supply side response, etc.

${ }^{2}$ The Russian tax is an income tax as opposed to a flat consumption tax as, for example, in Hall and Rabushka (1985).
} 
performance and beneficial changes in real economic activity. More recently, several other Eastern European countries (Serbia, Ukraine, Georgia, Romania, Slovakia, and Macedonia) have adopted flat rate income tax reforms. At the latest count, more than 20 countries have implemented or are about to implement some form of flat rate income tax following, many believe, Russia's steps (Sabirianova Peter et al. 2007). ${ }^{3}$

Russia's flat tax reform was quite revolutionary because it involved a large country and because it affected many people, not only the rich. But beyond the excitement Russia's flat tax reform has generated, so far very little solid evidence has been provided on its impact on tax evasion or real economic activity. As shown in Table 1, after a period with negative real growth and high inflation rates that culminated with the financial crisis of 1998, the Russian economy started a period of solid economic growth and more stable prices in 1999. By the time the flat rate of income tax was introduced in the Tax Code of 2001, real GDP had grown by 9 percent in 2000 and 5 percent in $2001 .^{4}$ At the same time, in the most striking performance, real collections from the personal income tax grew at close to 26 percent in 2001, the year of the reform, and continued to grow by 21 percent in 2002 and almost 12 percent in 2003; in post-reform years the growth rate declined significantly. This burst in collection performance for the new personal income tax can be explained by the better performance of the real economy, by improved voluntary compliance from taxpayers, and/or by stricter enforcement of the tax system via higher penalties and enforcement efforts by the tax authorities. ${ }^{5}$ Although real income grew during 2001 and the years after, the

\footnotetext{
${ }^{3}$ More recently, several OECD countries have been giving serious consideration to the adoption of flat tax reforms (see Owens 2007). In addition, several policy makers praised the Russian flat tax reform. For example, during a state visit of Russia's President Putin to the U.S. in 2001, President George W. Bush said, "I am impressed by the fact that [Putin] has instituted tax reform -- a flat tax. And as he pointed out to me, it is one of the lowest tax rates in Europe. He and I share something in common: We both proudly stand here as tax reformers."

${ }^{4}$ The strong growth in the post-reform period has been commonly associated with the favorable oil prices and the important role played by oil exports in the Russian economy during that period.

${ }^{5}$ An explanation based on higher penalties for tax evasion is the least plausible of the other alternative causes. A significant feature of the new Russian Tax Code was that it generally reduced the draconian tax penalties that had been in force during the 1990s. See Martinez-Vazquez, Rider, and Wallace (2008) for more details.
} 
figures in Table 1 suggest that something else may have been behind the significant increase in real collections from the personal income tax. Therefore, it would seem worthy to investigate the potential roles that improved voluntary compliance and better administration enforcement efforts may have played in the sharp increase in collections.

Measuring the level of tax evasion is notoriously difficult, requiring programs of random intensive taxpayer audits such as the Taxpayer Compliance Measurement Program (TCMP) conducted by the U.S. Internal Revenue Service (Slemrod 2007). Most countries, including Russia, have not carried out this type of program. In this paper, we use the difference between reported consumption and reported income, which we call the consumption-income gap, to detect the changes in tax evasion after the tax reform. ${ }^{6}$

Our approach is distinct from previous studies which also used data on income or expenditure composition to study tax evasion. This previous research typically uses a group of taxpayers who are known to comply (e.g., employees subject to withholding) as a benchmark to assess the true income of another group of taxpayers (e.g., self-employed). ${ }^{7}$ For Russia, we cannot use this "benchmark" approach because tax evasion was widespread, with employees quite likely practicing as much tax evasion as the self-employed. For example, employers and employees often have engaged in explicit and implicit agreements to conceal a part of wages to reduce the tax burden. The modes of tax evasion have included employees receiving compensation in the form of envelopes with cash, purchase of life insurance policies and other fringe benefits, interest from bank

\footnotetext{
${ }^{6}$ Our approach to detect tax evasion is broadly related to the literature utilizing discrepancies between different data sources to study evasion, cheating, smuggling, and other unreported activities. For example, Fisman and Wei (2004) use the difference between Chinese and Hong Kong customs data to assess the effect of duties on tax evasion. In a similar spirit, Marion and Muehlegger (2008) use the observed changes in diesel sales in response to dyeing untaxed diesel to infer evasion of taxes on diesel for on-road purposes.

${ }^{7}$ For example, the IRS in the U.S. reports that for 2001 filed returns, only 1 percent of wages and salaries were underreported, but that an estimated 57 percent of non-farm proprietor income was not reported (IRS 2006). Given this dichotomy of tax compliers and non-compliers, one can use the discrepancy between the two groups to approximate the level of tax evasion. For example, Pissarides and Weber (1989) exploit differences in food consumption; Lyssiotou, Pashardes, and Stengos (2004) look at differences in the composition of consumption; and Feldman and Slemrod (2007) examine differences in charitable contributions to impute income hidden from taxes.
} 
deposits made by the employer, not reporting income from a second job, failure to consolidate incomes from different sources, and so on. When tax evasion is present in all groups, using total expenditure and total income is more appropriate. ${ }^{8}$

Our approach is based on three pillars. The first is the identification of the treatment group based on after-reform reported income. The essential advantage of this identification strategy is that after the reform, households facing the flat marginal tax rate should have no behavioral response to the pre-reform tax rate thresholds. The second pillar is the consumption-income gap function that includes tax evasion determinants, life-cycle factors, consumption composition shifters as well as time-invariant unobservable household characteristics (and time-varying regional shocks in some specifications). The third pillar is the regression-discontinuity type estimation that provides a consistent estimate of the treatment effect at the point of discontinuity (the tax bracket threshold). In this case, the treatment effect is less likely to be confounded with other factors because taxpayers just below and just above the threshold as applied to the post-reform income are likely to be very similar (e.g., they should have the same probability of being subjected to the tax audit).

Together, these methods can effectively isolate the voluntary compliance response to tax changes from other factors such as increased enforcement effort by the tax administration, changes in saving behavior, credit market development, changes in the composition of consumption, supplementary revisions to the Tax Code, and so on. We estimate a relatively large tax evasion response of households to changes in tax rates, a $10-11 \%$ increase in reported income relative to consumption. In addition to estimating the tax evasion response, we also assess the productivity gains of the tax reform by estimating the consumption response to tax rate changes. Unlike the

\footnotetext{
${ }^{8}$ Similarly, the first comprehensive study of the Russian flat tax by Ivanova, Keen and Klemm (2005) uses the ratio of total income to total expenditures as a proxy for compliance and finds a statistically significant increase in the incometo-expenditure ratio among high earners one year after the Russian tax reform. However, largely due to methodological constraints and different focus, their study did not isolate the effect of tax changes on voluntary compliance from other confounding explanations for the increase in the income-to-expenditure ratio and concludes that "it remains unclear whether this [increase in compliance] was due to the parametric tax reform or to accompanying changes in enforcement" (p.398).
} 
taxable income response, the consumption response measures actual changes in resources available to households, and thus it is immune to tax evasion and income shifting activities. We find the productivity effect to be positive but small relative to the tax evasion effect.

These findings are important for social welfare calculations because, as Chetty (2008a) argues, welfare gains from tax cuts can depend on the ability of taxpayers to evade taxes, and one has to separate the productivity response from the evasion response to correctly compute deadweight losses from taxes. We develop a novel framework to assess the deadweight loss from personal income tax in the presence of tax evasion and we show that adjustments for tax evasion can significantly reduce the magnitude of these losses and the corresponding welfare gains from tax reform. By using both consumption and income responses to tax changes, we estimate that the deadweight losses adjusted for tax evasion are at least $30 \%$ smaller than the deadweight losses based on conventional approaches that utilize only the income response to tax changes. An important implication of these findings is that the adoption of a flat rate income tax can lead to significant reductions in tax evasion and increased tax revenues in countries where tax rates are high and tax evasion levels are significant. But these revenues are likely to come from better reporting and increased compliance, and much less from changes in labor supply and increased economic activity.

The paper also makes several methodological contributions to the empirical public finance literature. The paper offers a general approach to estimating the extent of tax evasion in different countries, provided there are available longitudinal household income-expenditure surveys and intermittent tax reforms with significant changes in tax burdens. Although these conditions will not always be met, the list of countries where the methodology can be applied far exceeds that of countries that implement extensive random audit programs to examine the extent of tax evasion. Also the paper: (i) suggests a methodology for separating tax evasion and productivity responses to 
changes in tax rates; (ii) shows that the response of consumption to tax changes is the right approach to calculating deadweight losses; and (iii) contributes empirical evidence on the relationship between tax rates and tax evasion, which has not been clearly established in past crosssectional studies

The remainder of the paper is organized as follows. In Section 2, we introduce our data and descriptive statistics. Next, in Section 3, we derive a tax evasion function using the difference in the $\log$ of consumption and income. In Section 4, we present the estimates of the tax evasion function. Sections 5 and 6 discuss methodological issues and provide the estimates of the flat tax effect using difference-in-difference and regression-discontinuity-type approaches. In Section 7, we investigate the productivity effect of the flat tax and develop a framework to assess the deadweight loss from personal income taxes in the presence of tax evasion based on the consumption response to tax changes. Finally, in Section 8 , we draw conclusions.

\section{Data and Variables}

We use the 1998, 2000-2004 rounds of the Russian Longitudinal Monitoring Survey (RLMS), a household panel survey which is based on the first national probability sample drawn in the Russian Federation and administered by the University of North Carolina. ${ }^{9}$ The panel structure of the data is useful in implementing before and after analysis while controlling for constant unobservable household and local characteristics in estimations. Having post-reform data for four consecutive years is particularly valuable for capturing the full extent of the response to tax rate changes since households may need some time to learn about implications of the reform, convince themselves that the reform is permanent, and make appropriate adjustments (see Johnson, Parker,

\footnotetext{
${ }^{9}$ We do not use the 1994-1996 rounds because of high macroeconomic volatility during this period, with annual inflation reaching $214 \%$ in 1994, and apparent noise in respondents' answers, especially, with regard to food items. In addition, the early questionnaires did not include contractual earnings, which are the key variable for our analysis as well as several important expenditure items such as medicine, car repair, etc. RLMS was not conducted in 1997 and 1999.
} 
and Souleles (2006) for a recent example of the dynamic response in the U.S.). There were 8,343 to 10,670 individuals who completed the adult (age 14 and over) questionnaire and 3,750 to 4,718 households who completed the household questionnaire in each round. These individuals and households reside in 32 oblasts (regions) and 7 federal districts of the Russian Federation. ${ }^{10}$

The key variables in our analysis are household consumption and household reported income. The household questionnaire contains detailed information on separate expenditure items purchased in the last 30 days (unless indicated otherwise): more than 50 items of food at home and away from home, alcoholic and non-alcoholic beverages, and tobacco products purchased in the last 7 days, ${ }^{11}$ expenses on clothing and footwear in the last 3 months; gasoline and other fuel expenses (3 subcategories); rents and utilities, and 15-20 subcategories of services (such as transportation, repair, health care services, education, entertainment, recreation, insurance, etc.). These expenditure items are aggregated into monthly consumption of non-durable items $(\mathrm{C} 1)$, which is our baseline measure of consumption. The second consumption measure (C2) adds transfer payments in the last 30 days (6 subcategories include alimonies and various contributions in money and in kind to individuals outside the household unit). Although transfer payments are not typically considered as part of consumption, households may derive extra utility from altruistic motives by transferring resources to relatives (Laitner and Juster 1996, Altonji, Hayashi and Kotlikoff 1997, Kopczuk and Lupton 2007). In addition to non-durable consumption items, households also report durables purchased in the last 3 months (10 subcategories include major appliances, vehicles, furniture, entertainment equipment, etc.). Combining one third of these durable purchases and $\mathrm{C} 1$

\footnotetext{
${ }^{10}$ Russia has 89 regions and 7 federal districts. The RLMS sample consists of the 38 randomly selected primary sample units (municipalities) that are representative of the whole country.

${ }^{11}$ Monthly expenditures on food are computed as the sum of weekly expenditures on individual food items multiplied by $30 / 7 \approx 4.286$. Since some food items are storable (flour, sugar, potatoes and vegetables) and expenditures on these goods tend to be seasonal (typically higher in the fall), we use top coding for unreasonably high amounts of food purchases conditional on household structure and food prices. The procedure of top coding of food items is described in Gorodnichenko, Sabirianova Peter and Stolyarov (2008a).
} 
gives us a third measure of monthly consumption (C3). For each expenditure item, it is known whether or not a household purchased the item, as well as the amount of the purchase. ${ }^{12}$

Total household income is the combined income of all household members after taxes from all jobs and other regular sources. The labor income is reported by the reference person as after-tax payments received by all household members from all places of work in the form of money, goods, and services in the last 30 days. Non-labor income includes pensions, stipends, unemployment benefits, rental income, interests and dividends, alimonies, and child care benefits. Our base income measure includes regular portions of labor and non-labor income, as defined above (Y1). The second income measure (Y2) adds irregular receipts from the last 30 days that consist of lumpsum payments from insurance, amounts received from the sales of material assets, and 11 subcategories of contributions from persons outside the household unit, including contributions from relatives, friends, charity, international organizations, etc. These irregular receipts are generally not included in the definition of income. ${ }^{13}$ Finally, since households may derive supplementary income from household production, we also calculate the third income measure (Y3) by adding Y1 and income from selling household-grown, mostly agricultural products. ${ }^{14}$ As with expenditures, missing income amounts for the subcategories of non-labor income, irregular receipts, and household production are imputed using the regression approach. Overall, imputations are minimal. Labor income is not imputed.

\footnotetext{
${ }^{12}$ When a household purchased the item but did not report the amount of the purchase, the missing amounts are imputed by regressing the log of expenditure on the complete interaction between year dummies and federal district dummies, controlling for the size of the household, number of children (18 years old or younger), and number of elderly members $(60+)$. The procedure is described in Gorodnichenko, Sabirianova Peter, and Stolyarov (2008a). The subcategories with the largest number of missing values include utilities $(2.1 \%$ of the sample), gasoline and motor oil $(1.6 \%)$, transportation services $(1.5 \%)$, and contributions to non-relatives (1.4\%). Missing values for other subcategories are trivial.

${ }^{13}$ A large component of the irregular income is private transfers (typically from relatives). Because these transfers are not taxed, taxpayers do not have strong incentives to conceal this source of income, and thus adding transfers does not affect tax evasion directly. However, Y2 can help us rule out explanations based on intra-family transfers in cases where households have large consumption because they are supported by other households.

${ }^{14}$ Income from household production is calculated by multiplying the amount of sold agricultural products (33 subcategories) and local price per unit of product (see Gorodnichenko, Sabirianova Peter and Stolyarov 2008a for details).
} 
We compare per capita consumption and income levels between RLMS and official National Income and Products Accounts (NIPA) in Figure 2. The RLMS measures of consumption and income are made comparable to the NIPA measures by using similar data definitions (see the notes to Figure 2). Consumer expenditures in RLMS and NIPA are close during most of the sample period, ${ }^{15}$ but reported disposable income in RLMS is as much as 30 percent lower than the official figures. While NIPA consumption and income data are internally consistent, ${ }^{16}$ RLMS reported income is always below consumption throughout the whole period, although the gap has been declining in recent years. ${ }^{17}$

This gap cannot be attributed to dissaving. First, most households had negligible stocks of financial assets by the mid 1990s. Second, the saving rate computed as the difference between reported income and expenditures would be equal to $-30 \%$ of income on average between 1994 and 2004. The dissaving of such a grand scale could not have lasted for ten consecutive years. Thus, the difference between reported income and consumption should not be used as a measure of saving, as some of the previous studies have done (e.g., Guariglia and Kim 2003). Instead, we compute gross saving as the sum of purchases of stocks, bonds, and other securities, current cash savings, and money lent. Figure 2 shows the gross saving rate of RLMS households and contrasts it with the saving rate in the Household Budget Survey (HBS), the official source of household income and expenditure statistics in Russia. Both sources show similar low and stable saving rate of households (3-6\%). To check the importance of borrowing for the consumption-income gap, we

\footnotetext{
${ }^{15}$ The 1998 discrepancy can be explained by the fact that the RLMS had been conducted right after the August financial crisis while NIPA's numbers were averaged over the year.

${ }^{16}$ NIPA eliminates the discrepancy between reported income and consumption by construction. Disposable income is constructed as the sum of household aggregate expenditures and savings, and the difference between imputed disposable income and the officially reported income is included in the income accounts as unobserved labor compensation.

${ }^{17}$ The design of the RLMS questionnaire makes it difficult for households to balance consumption expenditures with income: total consumption expenditures are never asked, questions on income and consumption are given in separate sections, and the questionnaire is filled out by the interviewer, not by an interviewee. Thus, households do not observe the totals for itemized incomes and consumption expenditures simultaneously to be able to match them. If households try to roughly match consumption to income, our estimates should be interpreted as a lower bound.
} 
also calculate net savings as the difference between the net change in financial assets and the net change in liabilities. ${ }^{18}$ The sum of $\mathrm{C} 1$ and net savings is defined as $\mathrm{C} 4$.

All monetary values at the household level are expressed in December 2002 prices and adjusted for regional cost-of-living differences by using the regional value of a fixed basket of goods and services. ${ }^{19}$

The household-level data are supplemented by individual information on the head of the household, including employment participation, earnings, age, schooling, tenure, and characteristics of the primary employer such as formal organization, ownership, location, and firm size. The head of the household is defined as the person with the largest income. If more than one individual within a household have similar incomes, then the oldest person is defined as the head of the household. In a few exceptional cases of multiple household members with the same age and income, the priority is given to the first person in the roster files.

\section{Conceptual Framework: Derivation of Tax Evasion Function}

Our theoretical starting point is the permanent income hypothesis (PIH) which suggests that consumption equals permanent income. Consequently, consumption contains important information about resources (income) available to households. If consumption consistently deviates from reported income holding everything else constant, one may suspect that some part of the income is not reported. In fact, tax authorities often use the discrepancy between income and expenditures to detect tax evasion. Thus, the differential between consumption and income can

\footnotetext{
${ }^{18}$ The net change in financial assets includes purchases of stocks, bonds, and other securities in the last 30 days, plus current cash savings in the last 30 days, minus sales of stocks, bonds, and other securities in the last 30 days, minus the amount of spent savings, foreign currency and valuables in the last 30 days. The net change in liabilities is computed as money borrowed in the last 30 days, minus money lent outside the household unit in the last 30 days, minus payments to creditors in the last 30 days, plus amounts received from debtors in the last 30 days.

${ }^{19}$ To adjust for monthly inflation, we express all flow variables in December prices of the corresponding year by using a country average monthly CPI and the date of interview. If the date of the interview is in the first half of the month, the previous month CPI is used. If the date of interview is in the second half of month, the current month CPI is used. Then the annual (December to December) CPI for each 32 oblasts (regions) is applied to convert the flow variables into December 2002 prices.
} 
inform us about whether and to what extent households evade taxes. In the rest of this section, we formalize this idea and develop an econometric specification of the tax evasion function.

Let $Y_{h t}^{*}$ be the (true) income received by household $h$ at time $t$. Households may choose to conceal a part of their income and report only $Y_{h t}^{R}=\Gamma_{h t} Y_{h t}^{*}$, where $\Gamma_{h t}$ is the fraction of reported current income. We can model $\Gamma_{h t}$ as a function of observable characteristics $S_{h t}$ that influence tax compliance: $\Gamma_{h t}=\Gamma\left(S_{h t}\right)=\exp \left(-\gamma S_{h t}+\right.$ error $)$. In addition to job and worker characteristics, the vector $S_{h t}$ might also include various central and regional government policies, in particular, the 2001 flat tax reform, which is our focus.

Further, let's assume that current household income $Y_{h t}^{*}$ is related to permanent income $Y_{h t}^{P}$ as $Y_{h t}^{*}=\mathrm{H}_{h t} Y_{h t}^{P}$, where $\mathrm{H}_{h t}=\mathrm{H}\left(X_{1, h t}\right)=\exp \left(\eta X_{1, h t}+\right.$ error $)$ captures deviations of current income from permanent income due to life cycle factors $X_{1, h t}$ such as age, schooling, employment participation, number of children, etc. and due to transitory shocks absorbed into the error term. Accounting for the life-cycle factors is necessary because the difference between permanent/lifetime income and current income exhibits strong life-cycle dynamics (e.g., Hubbard, Skinner, and Zeldes 1995, Gourinchas and Parker 2002, and Haider and Solon 2006).

Since service flows of durable goods are often unknown, we should further assume that expenditures on non-durables $C_{h t}$ constitute a fraction of permanent income, that is, $C_{h t}=\Theta_{h t} Y_{h t}^{P}$. This fraction is fixed if the consumption aggregator for durables and non-durables has a CobbDouglass form in the utility function. ${ }^{20}$ We allow the fraction $\Theta$ to vary across households. In

\footnotetext{
${ }^{20}$ We assume constant unitary income elasticity of consumption because we consider the total consumption of nondurables goods. The ratio of non-durables to income is fairly stable in macroeconomic data, which is consistent with the constant unitary elasticity. Although Pissarides and Weber (1989) and several subsequent papers allow the income elasticity to be different from one, those studies deal with food consumption and other specific goods instead of total consumption. We also note that even if the household survey had collected information on the value of durables, households have strong incentives to underreport consumption/ownership of durables because it is highly visible and indicative of true earnings. Hence, using that information to construct the service flow of durables and consequently
} 
particular, we let $\Theta_{h t}=\Theta\left(X_{1, h t}\right)=\exp \left(\theta X_{2, h t}+\right.$ error $)$, where $X_{2, h t}$ consists of the number of household members and number of children in order to account for economies of scale, while the number of elderly members, age, schooling, and marital status are included as taste shifters. This list of variables is commonly used in empirical consumption functions (e.g., Blundell et al. 1994, Browning and Lusardi 1996).

Given our assumptions, we obtain three important relationships:

$$
\begin{aligned}
& \ln Y_{h t}^{R}-\ln Y_{h t}^{*}=-\gamma S_{h t}+\text { error, } \\
& \ln Y_{h t}^{*}-\ln Y_{h t}^{P}=\eta X_{1, h t}+\text { error }, \\
& \ln C_{h t}-\ln Y_{h t}^{P}=\theta X_{2, h t}+\text { error. } .
\end{aligned}
$$

Even though $Y_{h t}^{*}$ and $Y_{h t}^{P}$ are not observable, we can still estimate our parameter of interest $\gamma$ if we combine equations (1a-1c) into the observed consumption-income gap function (2). Since vectors $X_{1, h t}$ and $X_{2, h t}$ are likely to overlap considerably, we let $X_{h t}$ be a union of $X_{1, h t}$ and $X_{2, h t}$ to simplify notation and write our final specification as

$$
\ln C_{h t}-\ln Y_{h t}^{R}=\gamma S_{h t}+\beta X_{h t}+u_{h}+\varepsilon_{h t},
$$

where $\gamma$ shows the effect of $S_{h t}$ on tax evasion; $u_{h}$ is a time-invariant component of the error term that accounts for risk aversion, preferences, and other constant household and local characteristics affecting consumption and/or income, and $\varepsilon_{h t}$ is a random error term. ${ }^{21}$

Following Pissarides and Weber (1989), Lyssiotou, Pashardes, and Stengos (2004), and others, we assume that the consumption of non-durables, which is our preferred measure of

total consumption would most likely underestimate the extent of tax evasion. Our results hardly change when we add the recent purchases of durables to the consumption of non-durables, as will be shown below.

${ }^{21}$ The consumption-income gap function has a convenient semi-log functional form. From the permanent income/lifecycle theory of consumption, the consumption-income ratio should be equal to one and the log of this ratio is zero. Thus, we can interpret the coefficients in equation (2) as percentage deviations of the consumption-income ratio from the "steady state". Using the log-ratio also improves the statistical properties of our estimates as the consumptionincome ratio and the error in income underreporting (Alexander and Feinstein 1987) are highly skewed. 
consumption, is correctly reported. This assumption is supported by the close match of consumption levels between RLMS and NIPA in Figure 2. We also assume that the income reported in the household survey is used for tax purposes. Ivanova, Keen, and Klemm (2005) argue that individuals may not fully believe in the anonymity of the survey and generally prefer not to reveal their illegal income. They show that the growth in imputed PIT payments in the RLMS sample almost exactly matches the growth in PIT revenues reported by the Ministry of Taxation of the Russian Federation. We also find average wage in RLMS to be within the sampling error of average wage from enterprise reports submitted to the state statistical agency.

On the right-hand side of equation (2), we have two vectors of covariates $S$ and $X$. The vector $S$ accounts for individual variation in tax evasion due to age, schooling, marital status, tenure, type of job (enterprise vs. self-employment), sector (private vs. public), and the firm size for the head of the household. It also contains year dummies and a trend variable for the after-reform period. Based on our earlier discussion, the vector $X$ includes age, schooling, marital status, employment participation, number of household members, number of children, and number of elderly members. Since some of the factors are present in both vectors (e.g., age, schooling, and marital status), we have to be cautious not to attribute the estimates solely to tax evasion. In summary, if proper controls are included, the consumption-income gap function (2) becomes a useful tool for analysis of tax evasion.

The permanent income hypothesis assumes that households have the ability to borrow and lend to smooth consumption. If this assumption does not hold, one may be inclined to use the cashon-hand as a chief determinant of consumption (instead of permanent income). ${ }^{22}$ In this case, the

\footnotetext{
${ }^{22}$ In Russia, the saving rate and the stock of financial assets are very low. However, the inability to borrow in formal credit markets can be mitigated by intra-family and public transfers, food storage, home production and other instruments that smooth consumption even when savings are low. Gorodnichenko, Sabirianova Peter, and Stolyarov (2008a) use the same dataset and find that Russian households have been able to partially smooth consumption in response to income shocks. In particular, they estimate that only $10-20 \%$ of transitory income shocks at monthly frequency are consumed at the time of the shock, which is consistent with other studies of consumption smoothing in
} 
consumption-income gap function continues to be the relevant tool for studying tax evasion because constrained households should spend all available after-tax income on consumption (equation (1b) can be omitted in this case). Therefore, violations of PIH are not likely to lead to any major distortions of our results in practice.

\section{Tax Evasion and Consumption-Income Gap}

In this section, we perform a series of estimations to verify that the consumption-income gap is an informative indicator of tax evasion behavior. First, we check whether our estimates of the consumption-income gap function are consistent with common tax evasion determinants reported in studies based on the TCMP and similar programs in other countries (e.g., Clotfelter 1983).

Table 2 reports household fixed effect estimates of specification (2) for four combinations of income and consumption. ${ }^{23}$ Although the coefficients on age, marital status, schooling and other demographic characteristics do not have clear structural interpretation in our reduced form specification, they are consistent with the results in the TCMP-based studies. For example, the sign of coefficients on age is consistent with other studies showing that the tax evasion is less likely among older (and risk-averse) workers (e.g., Clotfelter 1983). Married individuals are estimated to have a significantly smaller consumption-income gap. ${ }^{24}$ The estimated positive effect of tenure might be due to accumulated additional experience regarding tax evasion opportunities while working at the same job. Other variables enter the consumption-income gap function solely as tax evasion determinants. The coefficient on working at an enterprise (as opposed to being self-

Russia (e.g., Skoufias 2003). At the same time, consumption is found to be highly responsive to permanent income shocks.

${ }^{23}$ We experimented with other definitions of consumption, such as the one that uses a non-itemized food expenditure variable or the one that includes net change in financial worth (net savings). For these and other measures, we find similar results which we do not report. None of our results change when we control for the number of earners.

${ }^{24}$ This finding is opposite to what typically found in the U.S. literature (e.g., Feinstein 1991, Martinez-Vazquez and Rider 2005, Slemrod 2007). The marriage tax penalty and complex married return are two common explanations for why married individuals in the U.S. are more likely to evade. However, the Russian tax law does not allow for separate tax filing of married people, and the marriage tax penalty does not exist. 
employed) is negative and statistically significant, and it is consistent with previous U.S. studies showing that self-employed individuals tend to have higher noncompliance rates (Feinstein 1991, Feldman and Slemrod 2007, Slemrod 2007).

Firm size is another important determinant of tax evasion, but the previous literature provides mixed evidence. The size effect is found to be positive in the U.S. firm-level studies (Slemrod 2007), but negative for Cameroon businesses (Gauthier and Gersovitz 1997) and positive or negative depending on whether an individual taxpayer in Jamaica works in the private or public sector (Alm, Bahl, and Murray 1990). Our results show that the consumption-income gap is smaller for Russian workers employed in larger enterprises. Since larger firms are subject to more extensive tax-compliance monitoring, workers are less likely to have loopholes in underreporting their incomes. Larger firms also find it harder to implement tax evasion schemes with a variety of workers. $^{25}$

We also find that the gap is largest for workers in the state sector, which is in line with the finding by Gorodnichenko and Sabirianova Peter (2007), who show that a greater consumptionincome gap in the public sector in Ukraine reflects widespread corruption and bribery of public sector employees. Overall, estimated coefficients on control variables are broadly consistent with the results reported in evasion studies.

One may expect that households are more likely to evade in the local jurisdictions where people are skeptical about whether the majority of the population pays taxes. In 1998 and 2002 (coincidentally before and after the tax reform), the RLMS asked respondents questions on the attitudes of other people in the country towards paying taxes. We construct a district-level evasion perception index as the share of individuals who believe that most people don't pay taxes or pay

\footnotetext{
${ }^{25}$ The negative tax evasion effect of the firm size could also be linked to the employer size-wage premium literature (Brown and Medoff 1989). Employees of large firms earning a wage premium will have weaker incentives to seek additional employment in the shadow economy.
} 
taxes on less than half of their income and use it as an additional regressor in the consumptionincome gap function. ${ }^{26}$ We find an overwhelmingly strong relationship between the consumptionincome gap and the local evasion perception index. In the districts where people tend to believe that most people do not pay taxes, households indeed have a larger consumption-income gap (see Table 3). Thus, a consumption-income gap is likely to provide meaningful information about tax evasion at the household level.

Overall, the estimates of the consumption-income gap function are consistent with a tax evasion story and its common determinants. Obviously, tax evasion is a concealed act and therefore without audit data we cannot test directly whether the consumption-income gap truly captures the extent of latent tax evasion. However, indirect evidence supports our claim that the consumptionincome gap is related to tax evasion.

\section{Tax Evasion Function: Difference-in-Difference Approach}

\subsection{Identifying the Effect of Flat Tax Reform}

Apart from confirming our intuition that the consumption-income gap is informative about tax evasion, Table 2 contains another remarkable result: after being constant prior to 2001, the consumption-income gap started to continuously decline over time. Table 2, Panel B reports a large and statistically significant coefficient on the after-reform trend variable indicating an average 6-7\% decline in the consumption-income gap per year from 2001 to 2004 . The timing of the decline coincides with the Russian flat income tax reform and cannot be explained by changes in the saving rate which was stable for RLMS households during the period of our analysis.

\footnotetext{
26 The local evasion perception index is constructed for the 38 primary sample units that include highly populated metropolitan areas as well as remote rural areas. The differences in observable characteristics across primary sample units are well documented (e.g., Berger, Blomquist, and Peter 2008). The average index value of 0.53 suggests that the majority of population believes in widespread evasion in Russia. The variability of evasion perceptions across municipalities is also high, with the index ranging from 0.37 to 0.77 in 1998 and from 0.34 to 0.67 in 2002 . The evasion perception index tends to be larger in bigger cities.
} 
However, we cannot attribute the decline in the consumption-income gap solely to the flat tax reform because other events occurred at the same time. For example, the credit market boom in the 2000s may also have reduced the consumption-income gap by providing incentives to report income in order to obtain a housing mortgage or other credit lines. The 2001 tax reform by itself was comprehensive and was not limited to the changes in the personal income tax rates (Ivanova, Keen, and Klemm 2005). Among the most significant tax code changes are $i$ ) the replacement of separate contributions to four social funds by the unified social tax paid by employers at the overall reduced rate, ii) abolished rules for multiple job holders to submit tax declarations, iii) a considerably higher $35 \%$ rate for income received from gambling, prizes, voluntary insurance contributions and excessive interest in attempt to combat various schemes of tax avoidance, and $i v$ ) a new system of tax deductions providing incentives to declare income (Russian Tax Code 2000, see also Appendix 1 for the summary of key changes). ${ }^{27}$

In principle, the on-going reforms of tax administration might also have contributed to better income reporting. Available descriptive statistics, however, show ambiguous changes in the work of the tax administration. Using the Federal Tax Department archive, we have assembled timeseries information on tax audits and charges for tax law violations and reported these data in Table 4. Some measures favor the tax enforcement argument. For example, both the ratio of received to accrued additional tax payments due to tax audits and the number of blocked bank accounts for tax related violations did increase after $2000 .^{28}$ At the same time, the number of on-site tax audits, total amount of charges, and the number of managers and entrepreneurs charged for breaching tax law have declined considerably after year 2000, which could be due, in part, to less tax evasion caused

\footnotetext{
${ }^{27}$ Appendix 1 shows that many of these changes were irrelevant for a vast majority of taxpayers. At the same time, the cornerstone elements of the personal income tax system such as withholding of taxes by employers did not change.

${ }^{28}$ See also Gaddy and Gale (2005) for anecdotal evidence of greater tax enforcement after Vladimir Putin came into power.
} 
by the tax reform. If the tax enforcement argument is valid, then it could also explain some of the decline in the consumption-income gap after 2000.

As a first step in separating the tax evasion effect of reduced marginal rates from other factors, we use the difference-in-difference approach considering those who are affected by the flat tax reform (higher tax brackets) as a treatment group while those who are not affected (lower tax brackets) as a control group. In particular, we estimate the following specification:

$$
\ln C_{h t}-\ln Y_{h t}^{R}=\gamma S_{h t}+\beta X_{h t}+\mu d_{h t}^{\text {treat }}+\alpha\left(d_{h t}^{\text {treat }} \times D_{p}\right)+\psi D_{p}+u_{h}+\varepsilon_{h t}
$$

where $d_{h t}^{\text {treat }}=I\left(\tau_{h t}<\tau_{h t-1}\right)$ is a dummy variable indicating if the head of the household is in the treatment group (i.e., the group that experiences a decline in marginal tax rates conditional on $Y_{h t}^{*}$ ) and $D_{p}$ is a dummy variable for the post-reform period 2001-2004.

The difference-in-difference approach is a very attractive tool as it controls for non-tax factors that simultaneously affect control and treatment groups. The key element of equation (3) is the specification of the treatment and control groups which we discuss in the next subsection.

\subsection{Treatment and Control Groups}

Since the pre-reform marginal tax rates are correlated with the pre-reform level of current income, there is a potential source of endogeneity in equation (3) as the dummy variable $d_{h t}^{\text {treat }}$ can be correlated with the error term $\varepsilon_{h t}$. For example, households can endogenously fall into the treatment group due to their choice of income and other behavioral responses. ${ }^{29}$ This endogeneity problem is particularly acute when we use pre-reform reported income to classify taxpayers into treatment and control groups in the presence of tax evasion.

\footnotetext{
${ }^{29}$ See Triest (1998), Moffitt and Wilhelm (2000), and Auten and Carroll (1999) for exposition and a survey of the endogeneity problem as applied to labor supply and earnings responses without tax evasion.
} 
To understand the source of the biases, we re-write equation (3) in first differences, consider only two periods $t-1$ and $t$ (before and after the reform), and drop the subscript $h$ to simplify exposition:

$$
\Delta \ln C_{t}-\Delta \ln Y_{t}^{R}=\gamma \Delta S_{t}+\beta \Delta X_{t}+\alpha I\left(\tau_{t}<\tau_{t-1}\right)+\Delta \varepsilon_{t}
$$

where $\tau_{t}$ is the flat tax rate in year $t$ that is independent of income and $\tau_{t-1}$ is the pre-reform marginal tax rate as an increasing step function of current (reported and hidden) income $Y^{*}$. The relevant treatment group $I($.) consists of households experiencing a decline in the rate that they face (not the rate they decide to pay), defined on the basis of their total after-reform income that is $\tau_{t-1}\left(Y_{t}^{*}\right)-\tau_{t}\left(Y_{t}^{*}\right)>0$. If the flat tax reform has reduced tax evasion, then $\alpha$ should be negative, ceteris paribus.

Because $Y_{t}^{*}$ is not observable, suppose we use the pre-reform reported income to identify treatment and control groups. In this case,

$$
\begin{aligned}
\tau_{t-1}\left(Y_{t-1}^{R}\right)-\tau_{t}\left(Y_{t-1}^{R}\right) & =\tau_{t-1}\left(Y_{t-1}^{R}\right)-\tau_{t}\left(Y_{t}^{*}\right) \\
& =\underbrace{\left[\tau_{t-1}\left(Y_{t}^{*}\right)-\tau_{t}\left(Y_{t}^{*}\right)\right]}_{\text {true treatment }}-\underbrace{[\tau_{t-1}^{\left.\tau_{t-1}\left(Y_{t}^{*}\right)-\tau_{t-1}\left(Y_{t-1}^{*}\right)\right]}-\underbrace{\left[\tau_{t-1}\left(Y_{t-1}^{*}\right)-\tau_{t-1}\left(Y_{t-1}^{R}\right)\right]}_{\text {tax evasion bias } \geq 0},}_{\text {productivity bias } \geq 0},
\end{aligned}
$$

where the first equality follows from the flat tax in the post-reform period. Classification into treatment and control groups based on observed income is correct only when $\tau_{t-1}\left(Y_{t-1}^{R}\right)-\tau_{t}\left(Y_{t-1}^{R}\right)$ has the same sign as $\tau_{t-1}\left(Y_{t}^{*}\right)-\tau_{t}\left(Y_{t}^{*}\right)$. However, as this equation shows, the treatment group based on pre-reform reported income excludes wage earners that increase productivity and pass the threshold (i.e., $\left.\tau_{t-1}\left(Y_{t}^{*}\right)-\tau_{t-1}\left(Y_{t-1}^{*}\right) \geq 0\right)$. In addition, the treatment group also excludes households whose current income is in the upper brackets while the reported income is in the lower bracket (i.e., $\left.\tau_{t-1}\left(Y_{t-1}^{*}\right)-\tau_{t-1}\left(Y_{t-1}^{R}\right) \geq 0\right)$. These are the households who are most likely to be "treated" by the reduced tax rate. In other words, assignment into control group is affected by behavioral responses 
to tax changes. Since the response of the control group is contaminated with the response of the treated group, the difference between control and treatment groups constructed on the basis of prereform income is going to be smaller. As a result, such misspecification will produce an upward bias in the estimate of $\alpha$, implying that the effect of the flat tax reform on tax evasion is less likely to be found. ${ }^{30}$

Now suppose we use the post-reform reported income to identify treatment and control groups. One can interpret this approach as running the reform backwards from flat tax to a progressive tax scale. Under the flat tax, all taxpayers face the same marginal tax rate irrespective of income; therefore, the assignment into the treatment and control groups is not affected by behavioral responses to differential tax rates. In this case,

$$
\begin{aligned}
\tau_{t-1}\left(Y_{t}^{R}\right)-\tau_{t}\left(Y_{t}^{R}\right) & =\tau_{t-1}\left(Y_{t}^{R}\right)-\tau_{t}\left(Y_{t}^{*}\right) \\
& =\underbrace{\left[\tau_{t-1}\left(Y_{t}^{*}\right)-\tau_{t}\left(Y_{t}^{*}\right)\right]}_{\text {true treatment }}-\underbrace{\left[\tau_{t-1}\left(Y_{t}^{*}\right)-\tau_{t-1}\left(Y_{t}^{R}\right)\right]}_{\text {bias }(t)=\text { tax evasion bias } \geq 0},
\end{aligned}
$$

where the first equality again follows from the flat tax. Note that if we assume that post-reform income is fully revealed (i.e., $Y_{t}^{R}=Y_{t}^{*}$ ), then using post-reform income to identify the treatment effect (and treatment/control groups) yields unbiased estimates. Equations (5) and (6) also imply that the overall bias in defining the treatment group is likely to be smaller when we use the postreform income. ${ }^{31}$ Furthermore there should be fewer people affected by the tax evasion bias in year $t$ because there are no longer incentives for households to cluster just below the threshold, and

\footnotetext{
${ }^{30}$ To understand the sign of the bias, consider the following hypothetical case. Suppose there is an individual who receives 60,000 rubles before and after the reform (there is no productivity effect), and the reform reduces the marginal tax rate for people with more than 50,000 rubles in annual income. Before the reform, the individual evades taxes and reports only 40,000 rubles in earnings. After the reform, he reports 60,000 rubles. Also, assume that the genuine response of the control group is zero, that is, actual and reported income do not increase for this group because they continue to face the same tax rate. If the pre-reform reported income is used to identify the treatment group, then an individual would fall into the control group. In this case, the response of the control group would be large because taxpayers choose to underreport their income before the reform. It follows that holding everything else constant, the estimated treatment effect would be small because the response of the control group is large.

${ }^{31}$ The difference between $\operatorname{bias}(t-1)$ in equation (5) and $\operatorname{bias}(t)$ in equation (6) is $\tau_{t-1}\left(Y_{t}^{R}\right)-\tau_{t-1}\left(Y_{t-1}^{R}\right)$. If the reported income stays the same or increases after the reform due to either productivity response or better compliance, then the progressive income tax scale in $t-1$ implies that $\tau_{t-1}\left(Y_{t}^{R}\right) \geq \tau_{t-1}\left(Y_{t-1}^{R}\right)$, and thus $\operatorname{bias}(t-1) \geq \operatorname{bias}(t)$.
} 
therefore there would be fewer people whose true current income is above the threshold while their reported income is just below the threshold (see Section 6). At the same time, because taxpayers can conceal some income even when the tax schedule is flat and hence some misclassification of the treatment group taxpayers in the control group is inevitable, we underestimate the effect of the tax reform.

In summary, the flat tax reform itself provides a unique identification opportunity. Since all people face the same marginal tax rate, the flat rate cannot be correlated with the after-reform reported income. By applying the pre-reform rates to the post-reform income (or counterfactual rates), we can avoid the problem of reverse causality and provide a lower bound on the effect of reduced tax rates on tax evasion.

To understand another potential source of endogeneity, recall that $\varepsilon_{h t}$ is the composite error term that originates in the three equations $-1 \mathrm{a}, 1 \mathrm{~b}$, and $1 \mathrm{c}$. The second equation (1b) contains a transitory error component that might be correlated with the marginal tax rate. Unusually high income in one period is not generally consumed immediately. As a result, large transitory movements in current income can generate a negative serial correlation in $\left(\ln Y_{h t}^{*}-\ln Y_{h t}^{P}\right)$, which can lead to a negative correlation between $\left(\ln Y_{h t}^{*}-\ln Y_{h t}^{P}\right)$ and pre-reform marginal tax rates if the rates are positively associated with the pre-reform income (so called "reversion to the mean" problem, see Moffitt and Wilhelm 2000). Fortunately, in addition to actually received earnings, the RLMS provides information on contractual earnings that we can use to create treatment and control groups. Contractual earnings have a much smaller transitory component than the earnings actually received last month, and therefore they are less vulnerable to "the reversion to the mean" problem. ${ }^{32}$ To

\footnotetext{
${ }^{32}$ Contractual earnings are defined as the average monthly earnings after taxes over the last 12 months that the employee is supposed to receive regardless of whether or not it was paid on time. Thus, contractual earnings also help to deal with the problem of irregularity of payments and wage arrears. The coefficient $\alpha$ might be negative if the reform period coincided with a smaller volatility in actual earnings (wage arrears, which were quite prevalent in the earlier years of the transition, started to fall after 1998).
} 
further minimize the adverse effects of transitory shocks, we follow Gruber and Saez (2002) and use the 4-year average of contractual earnings in the post-reform period to construct treatment and control groups.

In light of the discussion in this subsection, we define the treatment group as households whose heads earned more than 3,625 rubles (net of tax and after a $1 \%$ contribution to the pension fund) per month from all reported jobs at least once or on average after the tax reform. This amount is equivalent to 50,000 rubles of gross annual earnings - an upper threshold for the $12 \%$ bracket under the 2000 annual budget law. With a 1\% contribution to the pension fund, the control group faces the same $13 \%$ marginal tax rate before and after the reform (see Figure 1). Thus, the design of the Russian reform not only offers a unique solution to the endogeneity of marginal tax rates by making the tax schedule flat, but also provides a 'clean' control group by keeping the same marginal tax rate for the lowest tax bracket. We also note that the definition of the treatment group is not affected by standard tax deductions, which cannot be claimed by individuals earning more than 20,000 rubles per year (Russian Tax Code 2000).

We report selected statistics describing the treatment and control groups in Appendix Table A1. In short, households in the treatment group, which comprises of about $35 \%$ of all households, are larger and have more children, and the heads of those households are younger, more educated, and more likely to be married and employed than households in the control group. Working heads of households in the treatment group also have less experience with the same employer and tend to work in the private sector and larger firms.

\subsection{Estimates of the Tax Evasion Response}

Table 5 reports the estimates of equation (3), with the treatment group defined on the basis of post-reform actual earnings received last month. We find a large and significant decline in the consumption-income gap for the treatment group after 2000. The estimate of $\alpha$ is in the range 
between -0.11 and -0.09 , suggesting that income grew by approximately $9-11 \%$ more than consumption, ceteris paribus. Figure 3 illustrates a clear structural break in the consumptionincome gap dynamics in 2001 for both groups and a more pronounced decline for the treatment group. The fact that the consumption-income gap decreases for the control group by approximately $0.17 \log$ points shows the importance of other factors such as developments in credit markets, enhancements in tax administration and enforcement, etc. However, there still remains a significant fraction $[0.11 /(0.11+0.17) \approx 39 \%]$ of the decline in the consumption-income gap for the treatment group that can be attributed to changes in tax rates.

Table 6 shows the estimates of $\alpha$ from several alternative specifications of the treatment group that use contractual earnings. The estimates of $\alpha$ based on contractual earnings are negative and statistically significant, but they are slightly smaller in magnitude than the estimates based on the actual earnings received in the last month. As follows from our earlier discussion of the reversion to the mean problem, the measures of earnings that contain a large transitory component tend to overstate in absolute terms the effect of the treatment on the consumption-income gap. This is exactly what we find when we compare the estimates based on these two measures of earnings.

We also restrict the sample to the households whose head's implied gross annual earnings are between 20,000 and 100,000 rubles and apply the above definition of the treatment group to the restricted sample. We use the restricted sample to remove the influence of standard deductions and eliminate the differential effect of the regressive unified social tax paid by employers (see Appendix 1). For each worker in the restricted sample, employers should pay the same $35.6 \%$ rate of the unified social tax after 2000. Another benefit of the restricted sample is that the treatment group would have faced the same $20 \%$ rate if the pre-reform tax scale had remained after 2000 (the next $30 \%$ bracket begins with 150,000 rubles). As a robustness check, we excluded households with recent purchases of real estate and sizeable education expenses in order to avoid the potential 
contamination of treatment and control groups due to the housing and social deductions described in Appendix 1. In another robustness check, we excluded households with the recent purchases of real estate, vehicles, and stocks that title organizations are required to report to tax authorities.

According to the earlier Russian tax law, tax brackets were not automatically adjusted for inflation, and thus, an increase in nominal wages could push taxpayers into higher tax brackets ("bracket creep" effect). To assess the consequences of inflation adjustment, we apply the same criteria of the restricted sample to the earnings adjusted for inflation in December 2000 prices. The treatment group is also defined after deflating the post-reform income to December 2000 prices. Finally, we add interactions between district dummies (at the county level) and year dummies to control for changes in regional characteristics such as the degree of credit market development, tax enforcement, and other time-varying regional factors. We also allow individual and firm characteristics to have different effects before and after the reform.

Regardless of modifications in specifications, samples, and definitions of income and consumption, the magnitudes of $\alpha$ coefficients are large and vary from -0.126 to -0.091 for monthly contractual earnings. ${ }^{33}$ Using the 4-year average of post-reform contractual earnings gives similar estimates. Even when we replace the dummy variable for the post-reform period by the post-reform time trend, we obtain a large and statistically significant decline in the consumptionincome gap for the treatment group over time. The estimates vary from -0.044 to -0.031 . In summary, we find that the households experiencing a decrease in the marginal tax rate have a greater reduction in the consumption-income gap.

To verify that our results make economic sense, we also test if a decline in the consumptionincome gap is larger for individuals who are more likely to switch to tax compliance after the tax

\footnotetext{
${ }^{33}$ We do not adjust our estimates for changes in the volatility of the error term because the variability in both consumption and income was slowly decreasing over time. See Gorodnichenko, Sabirianova Peter and Stolyarov (2008a) for more details.
} 
reform. Only individuals with potentially legitimate labor incomes can reveal their true earnings. For example, it is unlikely that employees in the public sector will disclose the portion of their income that originates from bribes and other forms of corruption, no matter how low tax rates are. At the same time, the majority of employees in the private sector, as well as the self-employed, can report their earnings since there is often nothing criminal in their labor market activity. Hence, the consumption-income gap should decrease more strongly for the private sector workers than for employees in the public sector.

In addition, Russian private firms have greater incentives to compensate skilled workers who earn greater wages in ways that reduce their wages reported for tax purposes. After the reform the tax pressure is smaller, and hence the consumption-income gap should decline more for skilled than unskilled workers. To test these two predictions, we modify the baseline specification (3) with additional interaction terms. We report results in Table 7. Consistent with theoretical predictions, the decline in the consumption-income gap is largest for private sector employees and for white collar workers within the private sector.

Finally, we extend our baseline estimates of the consumption-income gap dynamics by accounting for changes in saving, expenditures on durables, and home production. ${ }^{34}$ First, we note that growth of durable purchases and a decline in production of home-grown food should increase the consumption-income gap, not decrease it. Only a reduction in net saving will be consistent with the declining gap. To examine the importance of these factors for our treatment effect estimates, we use alternative definitions of income and consumption that include components such as purchases of durable goods (C3), net savings (C4), and net income from home production (Y3). These alternative measures of consumption and income yield estimates of the treatment effect (Table A2)

\footnotetext{
${ }^{34}$ Because net savings and durable purchases are highly volatile and irregular, we use these components only in supplementary (not primary) specifications. Unfortunately, our data do not allow us to calculate the service flow of durables, which is the appropriate measure of durable consumption.
} 
similar to what we observe for our baseline definitions of income and consumption. We also do not find a differential response in the saving rate, share of expenditures on durables, or share of income from home production for treatment and control groups between 1998-2000 and 2001-2004. As a result, our treatment effect estimates remain largely unaffected by alternative specifications.

\section{Tax Evasion Function: Examining the Response around the Threshold}

The DID approach assumes that the treatment impacts subjects uniformly, while in practice the strength of the treatment effect may be heterogeneous. For example, the response of upperincome households to changes in marginal tax rates can be different from the response of middleincome households. It is also possible that subjects are heterogeneous in ways that are difficult to control for due to unknown specification of functional forms, unobservables, etc. The DID estimates might be contaminated by the differential evasion response of treatment and control groups to the various shocks and policy changes that coincided with the introduction of the flat tax such as tax administration reform. Even though we control for the local differences in tax enforcement via interacting district and year dummies, it is still possible that the negative $\alpha$ might be attributed in part to collection efforts if tax enforcement focuses primarily on those households who are more likely to be in the treatment group (i.e., high earners). ${ }^{35}$

Discontinuity of marginal tax rates at the known threshold values of income provides an opportunity to use the regression discontinuity (RD) design to assess and validate our results from the difference-in-difference approach. Under certain, relatively mild assumptions this alternative approach can address the issues we discuss above, and provide a consistent estimate of the treatment effect at the point of discontinuity (threshold income). Since subjects just below and just above the threshold as applied to the post-reform income are likely to be similar (e.g., they should

\footnotetext{
${ }^{35}$ For example, Gaddy and Gale (2005) cite the efforts of the Moscow tax police to organize a serious enforcement campaign aimed at wealthy individuals sheltering income.
} 
have the same probability of being subjected to the tax audit or the same propensity to consume durables), the treatment effect is less likely to be confounded with other factors. When the subjects are drawn from the same part of the income distribution, and they are minimally different along the dimension that determines whether a subject is treated or not, then one can consider the assignment of treatment as if it is random.

We do not have a sufficient number of observations to implement RD in its classical form, however we can use the RD intuition and apply weights to the DID regression, with weights as a decreasing function of the distance from the threshold. Specifically, we estimate parameters by minimizing

$$
\sum_{h=1}^{N} \omega_{h p}\left\{\ln C_{h t}-\ln Y_{h t}^{R}-\gamma S_{h t}-\beta X_{h t}-\mu d_{h t}^{\text {treat }}-\alpha\left(d_{h t}^{\text {treat }} \times D_{p}\right)-\psi D_{p}-u_{h}\right\}^{2},
$$

where $\omega_{h p}$ is a fixed household-specific weight calculated on the post-reform income. For any year $t$ in the post-reform period $p$, the weight is calculated as $K\left(\frac{\ln Y_{l t}^{R}-\ln Y_{t}^{*}}{b}\right) / \sum_{s=1}^{N} K\left(\frac{\ln Y_{s t}^{R}-\ln Y_{t}^{*}}{b}\right)$, where $K($.$) is$ the Gaussian kernel, $Y_{t}^{\#}$ is the threshold income at which marginal tax rate changes, and $b$ is the optimal "plug-in" bandwidth for the Gaussian kernel. The weight is a function of the distance between the individual post-reform income and the pre-reform threshold value with higher weights given to the observations that are closer to the threshold. We refer to equation (7) as the weighted difference-in-difference (WDID) estimator.

Imbens and Lemieux (2008) suggest that this approach to estimating RD or RD-type treatment effects has a number of advantages. First, although we put a small weight on observations distant from the threshold, we can use more information contained in the sample. ${ }^{36}$ Second, estimation and inference are straightforward since one can use the standard method of weighted least squares. Third, we can easily control for other factors to further ensure that just-

\footnotetext{
${ }^{36}$ Given an optimal bandwidth, taxpayers with income $43 \%$ below or above the threshold gross income of 50,000 rubles receive a weight less than 0.01 .
} 
below and just-above samples are balanced along dimensions other than income. Thus, weighed DID serves our purposes well since it has desirable statistical properties and preserves RD intuition.

Again, for the same reasons discussed in Section 5, we use the post-reform income in identifying the treatment group and calculating the weights. It is especially important for the RDtype estimates, which are based on the assumption that the running variable (income) should not have jumps at points where a marginal tax rate changes. In other words, there is no behavioral response to the threshold. This is not the case with the pre-reform income. Figure 4 reveals that reported contractual earnings are clustered just below the threshold value (vertical line) in the year 2000, but not in 2001. ${ }^{37}$ This clustering prior to the reform manifests a behavioral response to the discontinuity in the marginal tax rates. For example, households may choose to earn more income (above the threshold) but report less just to be located at the point where their reported income is taxed at the minimum rate. Clearly, we cannot use RD-type estimation when the treatment and control groups are defined on the basis of pre-reform income. In contrast, using the post-reform income satisfies the RD assumptions as the density of reported income exhibits no lumping around the threshold.

We estimate equation (7) and report results in Table $8 .{ }^{38}$ Generally, the WDID estimates of $|\alpha|$ are slightly larger than the DID estimates, although the difference between the estimates is not statistically significant. Factors that could have pushed WDID estimates up or down relative to DID estimates approximately cancel out. On the one hand, an estimate of $|\alpha|$ is likely be smaller in

\footnotetext{
${ }^{37}$ Respondents tend to report rounded figures for their incomes, and this can explain spikes in histograms.

${ }^{38}$ We perform a number of specification checks to verify that assumptions underlying RD-type estimation are satisfied. The running variable (post-reform income) does not exhibit jumps at points where marginal tax rate changes. The density of post-reform income is continuous in the relevant range. The estimated effect is fairly insensitive to the choice of bandwidth. The estimate of the effect somewhat decreases in absolute value as we shrink the bandwidth. We find little evidence that the consumption-income gap has jumps at the levels of income not associated with changes in marginal tax rates (that is, we do not observe changes in the consumption-income gap at points of income that are not associated with changes in the marginal tax rates). We cannot exploit another discontinuity at the income of 150,000 rubles per year when the marginal tax rate changes from $21 \%$ to $31 \%$ because we have a small number of households in the top bracket.
} 
WDID than in DID if the households that are further away from the threshold (e.g., upper-income taxpayers experiencing the largest drop in the marginal tax rate) are more sensitive to changes in the marginal tax rate. On the other hand, an estimate of $|\alpha|$ should be bigger in WDID if upper-income households respond less strongly than households closer to the threshold. For example, households with high incomes may continue to find it imprudent to report all income as the risk of expropriation by the government or criminals could be so significant that it outweighs the benefits of switching to tax compliance. The net effect of these forces is roughly zero as WDID and DID estimates are close to each other.

Similar to the DID estimates, the WDID estimates based on contractual earnings are somewhat smaller than the estimates based on earnings actually received in the last month. Overall, the WDID estimates strongly support our earlier finding that the consumption-income gap fell for the treatment group after $2000 .^{39}$

\section{Welfare Analysis}

Our findings so far indicate a positive effect of the Russian flat tax reform on income reporting relative to consumption. The next question we would like to address is whether the reform expanded productive opportunities available to households. Such productivity effects of tax reforms may come from changes in hours of work, labor participation, efforts, job reallocation, occupational mobility and many other behavioral responses, which are typically measured by changes in earnings or taxable income in response to tax rate changes (e.g., Feldstein 1995, Aarbu and Thoresen 2001). However, in the presence of tax evasion, an observed increase in earnings could be due to productivity effects and due to better reporting and compliance. In this section, we argue that one needs to look at the consumption side to separate these two effects.

\footnotetext{
39 To account for the possibility of taxpayer misclassification into treatment and control groups at the cutoff point, we also experimented with excluding taxpayers with incomes within one percent deviation from the threshold. In these experiments, the WDID estimates are very similar to our baseline estimates and hence not reported.
} 
Changes in consumption should reflect changes in total resources available to households.

After controlling for the windfall gains due to lower taxes, the response of consumption to tax changes can capture to what extent people choose to increase their true income (permanent or current depending on how much households can smooth consumption). This would be a genuine productivity effect of the tax reform on the real side of the economy which is a relevant variable for welfare calculations. In contrast, changes in reported income consist of productivity and tax evasion effects. As Chetty (2008a) argues, the latter effect can be irrelevant for welfare calculations since shifting resources across agents in the economy does not affect social welfare as long as this shifting does not alter the size of the 'pie' available to all agents. ${ }^{40}$

\subsection{Theoretical Framework}

To formalize these ideas, we follow Chetty (2008a) and assume that workers maximize their utility,

$$
\begin{aligned}
& u(C, l, e)=C-\psi(l) \\
& \text { s.t. } C=(1-t)(w l-e)+e-z(e, t)-g(e)
\end{aligned}
$$

where $C$ is consumption, $w$ is wages, $l$ is labor supply, $e$ is the amount of unreported earnings, $t$ is tax rate, $\psi(l)$ is disutility of labor, $z(e, t)=p(e)(e t+F)$ is the expected cost of being caught and fined or the expected transfer cost of tax evasion, $p(e)$ is the probability of being caught and fined, $F$ is the fixed penalty for evasion that can include both legal fines and bribes, and $g(e)$ is the real

\footnotetext{
40 Slemrod (1992) and others emphasize that the real response reflects how the tax system affects productive opportunities available to firms and individuals, while tax avoidance such as income shifting across time, accounts, branches, etc. does not influence the size of the 'pie' available to the society. In this respect tax avoidance (legal income shifting) is very similar to tax evasion (income underreporting). Both avoidance and evasion may overstate the deadweight losses from income taxes and thus have similar implications for welfare calculations. The consumption response that we rely on is also insensitive to whether resources available to the household come from evasion or avoidance. For these reasons, we do not make a clear distinction between avoidance and evasion in the paper. In the Russian context, however, tax evasion rather than tax avoidance was the dominant channel for minimizing tax burdens. The ability of Russian households to shift income across types of income with potentially different tax rates was very limited. The average share of capital income and insurance payments in RLMS is less than $1 \%$ of reported disposable income. Our estimates are not sensitive to excluding households with greater abilities to shift their income, e.g., those with capital income, insurance payments, and entrepreneurial income (less than $3 \%$ of our sample) (see Appendix 1).
} 
(resource) cost of evasion (e.g., the loss in profits from transacting in cash instead of electronic payments). As will be clear later, the key difference between our approach and previous analyses such as Feldstein (1999) is the presence of the transfer cost of evasion. In particular, our approach generalizes Feldstein's approach to cases when tax evasion has both transfer and resource costs. The corresponding first order conditions are $(1-t) w-\psi^{\prime}(l)=0$ and $t-g^{\prime}(e)-z_{e}^{\prime}(e, t)=0$.

The social welfare function is given by $W=u(C, l, e)+z(e, t)+t(w l-e)=w l-g(e)-\psi(l)$. Note that $z(e, t)$ is a pure transfer and therefore is irrelevant for social welfare. The marginal change in welfare in response to the tax change is simply

$$
\begin{aligned}
\frac{\partial W}{\partial t} & =\frac{\partial w l}{\partial t}-\frac{\partial g}{\partial e} \frac{\partial e}{\partial t}-\frac{\partial \psi}{\partial l} \frac{\partial l}{\partial t} \\
& =\frac{\partial w l}{\partial t}-\frac{\partial g}{\partial e} \frac{\partial e}{\partial t}-(1-t) w \frac{\partial l}{\partial t}=t \frac{\partial w l}{\partial t}-\frac{\partial g}{\partial e} \frac{\partial e}{\partial t}
\end{aligned}
$$

where the second equality follows from the first-order condition of utility maximization with respect to labor supply. Consequently, the relative change in welfare due to income taxes can be obtained as

$$
\epsilon_{W}=\frac{1}{w l} \frac{\partial W}{\partial t}=\frac{t}{w l} \frac{\partial w l}{\partial t}-\frac{g^{\prime}(e)}{t} \frac{e}{w l} \frac{\partial e}{\partial t} \frac{t}{e}=\epsilon_{w l}-\mu \frac{e}{w l} \in_{E}
$$

Equation (9) highlights the three crucial pieces needed for welfare calculations: $i$ ) the elasticity of total earned income to tax rates $\left.\epsilon_{w l} ; i i\right)$ the elasticity of evasion to tax rates $\epsilon_{E}$ adjusted by the share of evaded income in total income $\frac{e}{w l}$; and $\left.i i i\right)$ the fraction of the marginal cost of evasion accounted for by the resource cost $\mu=g^{\prime}(e) / t$.

From the first order condition for tax evasion, we have an upper bound on the last piece, the share of marginal resource cost of tax evasion, $\mu=g^{\prime}(e) / t \leq 1$, provided that $z_{e}^{\prime}(e, t) \geq 0$. This implies that the change in welfare due to income taxes should be between $\left|\epsilon_{w l}\right|$ (when the cost of 
evasion is a pure transfer or $\mu=0$ ) and $\left|\epsilon_{w l}-\frac{e}{w l} \in_{E}\right|$ (when there is no transfer cost of evasion or $\mu=1$ ). In the case of zero transfer cost, equation (9) simplifies to

$$
\in_{W}=\frac{1}{w l} \frac{\partial W}{\partial t}=\frac{1}{w l}\left(t \frac{\partial w l}{\partial t}-\frac{\partial g}{\partial e} \frac{\partial e}{\partial t}\right)=\frac{1}{w l}\left(\frac{\partial(w l-e)}{\partial t} t\right)=\frac{w l-e}{w l}\left(\frac{\partial(w l-e)}{\partial t} \frac{t}{(w l-e)}\right)=\left(1-\frac{e}{w l}\right) \in_{T I}
$$

where the third equality follows from the first order condition for $e\left(t-g^{\prime}(e)=0\right)$, and $\in_{T I}$ is the elasticity of taxable income with respect to tax rates, which is linked to the elasticity of after tax income $\epsilon_{Y}$ by $\in_{T I}=\epsilon_{Y}+\frac{t}{1-t}$. Thus, under the assumption of zero transfer cost of evasion, the elasticity of taxable income is a sufficient statistic for assessing welfare losses from income taxes, as shown by Feldstein (1999). Our approach relaxes this assumption and provides a more general framework to assess welfare losses from income taxes. We show below that $\in_{w l}$ and $\frac{e}{w l} \in_{E}$, the key pieces of equation (9), can be estimated from the available data on consumption and income.

Using the budget constraint, one can find that

$$
\begin{aligned}
\frac{\partial C}{\partial t} & =-(w l-e)+(1-t) \frac{\partial(w l-e)}{\partial t}+\frac{\partial e}{\partial t}-\frac{\partial g}{\partial e} \frac{\partial e}{\partial t}-\frac{\partial z}{\partial t}-\frac{\partial z}{\partial e} \frac{\partial e}{\partial t} \\
& =-(w l-e)+(1-t) \frac{\partial w l}{\partial t}-\frac{\partial z}{\partial t}+\underbrace{\left(t-\frac{\partial g}{\partial e}-\frac{\partial z}{\partial e}\right)}_{=0} \frac{\partial e}{\partial t} \\
& =-(w l-e)+(1-t) \frac{\partial w l}{\partial t}-\frac{\partial z}{\partial t},
\end{aligned}
$$

where the last equality follows from the first order condition for $e$. The first term in this expression is the marginal change in the after-tax reported income holding the reported income constant. The second term is the after tax response of earned income. The last term is the marginal change in the penalty, $\partial z / \partial t=p(e) e$.

Now we can link the elasticity of the consumption response to tax rates $\in_{C}$ and the elasticity of the earned income response to tax rates $\in_{w l}$ as follows: 


$$
\begin{aligned}
\epsilon_{C} \equiv \frac{\partial C}{\partial t} \frac{t}{C} & =-\frac{t(w l-e)}{C}+(1-t)\left(\frac{\partial w l}{\partial t} \frac{t}{w l}\right) \frac{w l}{C}-p(e) \frac{t e}{C} \\
& =-\kappa+\in_{w l} \underbrace{\left(\frac{(1-t) w l}{(1-t) w l+t e-z(e, t)-g(e)}\right)}_{s_{L}}-p(e) \underbrace{\left(\frac{t e}{(1-t) w l+t e-z(e, t)-g(e)}\right)}_{s_{E}} \\
& =-\kappa+\epsilon_{w l} \underbrace{}_{L}-p(e) s_{E},
\end{aligned}
$$

where $\kappa$ is the effective tax rate defined as the ratio of paid tax liability to household consumption, $s_{L}$ is the consumption share of after-tax resources a household would have if it paid taxes from the full amount of its true income, and $s_{E}$ is the share of the gross gains from evasion (te) in total household consumption. It follows that

$$
\epsilon_{w l}=s_{L}^{-1}\left(\epsilon_{C}+\kappa+p(e) s_{E}\right)
$$

The value of $p(e) s_{E}$ is negligible and can be safely omitted. For example, if the marginal tax rate is $20 \%$ (our baseline case) and people evade on a third of their income (which seems to be a plausible upper bound given various estimates in the literature and the consumption to income ratios in our sample), $s_{E} \approx 0.2 \times 0.3=0.06$. Since the probability of being caught is typically a few percent, then $p(e) s_{E} \approx 0$.

The share of net gains from tax evasion $t e-z(e, t)-g(e)$ in household consumption is even smaller than $s_{E}$, and thus $s_{L}$ should be just slightly below 1 , or $s_{L} \approx 1 .{ }^{41}$ It follows that $\in_{w l} \approx \in_{C}+\kappa$ and one can use the elasticity of consumption response adjusted for the effective tax rate as an approximate measure of the elasticity of total (true) income response. Importantly, the elasticity of consumption response is similar to Feldstein's (1999) elasticity of the taxable income response in the sense that it works like a sufficient statistic absorbing adjustments along many margins. ${ }^{42}$

\footnotetext{
${ }^{41}$ In general equilibrium, an entry into the tax evasion sector would eliminate abnormal profits from tax evasion. Likewise, regulation could respond strongly to very 'profitable' tax evasion activities. For example, the IRS and tax administrations in other countries regularly update the list of banned off-shores, accounting practices, etc.

${ }^{42}$ Chetty (2008b) provides detailed discussion on the importance of sufficient statistics for welfare analysis.
} 
The remaining piece $\frac{e}{w l} \in_{E}$ in equation (9) is approximately $\in_{C}-\frac{Y}{C} \in_{Y}$, where $\epsilon_{Y}$ is the elasticity of after-tax reported income $Y=(w l-e)(1-t)$ with respect to tax rates. This result follows from the budget constraint $C-Y=e-z(e, t)-g(e)$, which implies

$$
\frac{\partial C}{\partial t}-\frac{\partial Y}{\partial t}=\frac{\partial e}{\partial t}\left(1-\frac{\partial z}{\partial e}-\frac{\partial g}{\partial e}\right)-\frac{\partial z}{\partial t}=\frac{\partial e}{\partial t}(1-t)-p(e) e=\frac{w l(1-t)}{e} \frac{e}{w l} \frac{\partial e}{\partial t}-p(e) e
$$

The last equation expressed in terms of elasticities is $\in_{C}-\frac{Y}{C} \in_{Y}=s_{L} \frac{e}{w l} \in_{E}-p(e) s_{E}$, which simplifies to $\frac{e}{w l} \in_{E} \approx \epsilon_{C}-\frac{Y}{C} \in_{Y}$ given our earlier approximations $s_{L} \approx 1$ and $p(e) s_{E} \approx 0$.

Putting all the pieces together, we re-write equation (9) as $\epsilon_{W} \approx \epsilon_{C}+\kappa-\mu\left(\in_{C}-\frac{Y}{C} \in_{Y}\right)$, and provide lower and upper bounds on welfare changes due to income taxes:

$$
\left|\epsilon_{C}+\kappa\right| \leq\left|\epsilon_{W}\right| \leq\left|\frac{Y}{C} \in_{Y}+\kappa\right|
$$

This formula contains only observable quantities as we can estimate the elasticity of consumption to tax changes $\epsilon_{C}$, the elasticity of reported after-tax income to tax changes $\in_{Y}$, the effective tax rate $\kappa$, and the income-consumption ratio using consumption and income data. Equation (11) also puts bounds on the deadweight loss (DWL) from personal income taxes: $D W L_{W}=-0.5 t \in_{W} /\left(1-\frac{e}{w l}\right)$ of taxable income. ${ }^{43}$

In contrast to our approach based on the response of consumption to tax changes, the conventional approach developed in Feldstein (1999) uses the elasticity of taxable income with respect to tax changes $\epsilon_{T I}$ to quantify welfare losses as $D W L_{T I}=-0.5 t \in_{T I}$ of taxable income. If evasion is negligible $(e \approx 0)$ or it has no transfer cost, these two approaches provide the same estimate of welfare losses. Our and Feldstein's approaches will diverge with $D W L_{W}<D W L_{T I}$, when tax evasion has transfer cost. The smaller the share of marginal resource cost $\mu$, the closer the

\footnotetext{
${ }^{43}$ Following Feldstein (1999), the DWL is computed as the area of Harberger's triangle.
} 
true deadweight loss estimate approaches our lower bound based on $\epsilon_{C}+\kappa$. This latter case is highly applicable for the cash-based economies with a large shadow sector, and thus our lower bound of DWL should be particularly useful in the Russian context. Intuitively, since consumption net of any tax windfall gains responds only to changes in earned income rather than income shifting activities, our approach would provide a better estimate of DWL than the conventional approach based on taxable income. Table 9 summarizes the comparison of our and Feldstein's approaches.

\subsection{Productivity Effect of Flat Tax Reform}

In this section, we estimate the elasticity of total earned income response $\epsilon_{w l}$, the key component in welfare calculations that measures the productivity effect of flat tax reform. We begin by estimating consumption and income equations using the consistent sample and the same set of control variables (including household fixed effects) as in equation (3). Given the same set of controls, this is equivalent to the estimation of both equations by the seemingly unrelated regression (SUR) method. Again, our key parameter is the coefficient on the interaction term between the treatment group and a dummy for the post-reform period. As follows from the SUR properties, if we subtract the estimate of this coefficient in the consumption equation from the one in the income equation we should obtain exactly the estimate of $\alpha$ in the consumption-income gap function shown in Tables 5 and 6.

Table 10 reports the treatment effect estimates from the two systems of simultaneous equations: $\ln \mathrm{Y} 1$ and $\operatorname{lnC} 1$ as one system, and $\ln \mathrm{Y} 2$ and $\operatorname{lnC} 2$ as another one. ${ }^{44}$ Other combinations of income and consumption equations produce similar results and are not reported. The DID estimates provided in Table 10 indicate a large increase in reported income (18-19\%) for the treatment group following the tax reform, but there is also a significant (although smaller) increase

\footnotetext{
44 The full specification of the income and consumption equations, $\ln Y 1$ and $\ln C 1$, is provided in Appendix Table A3.
} 
in consumption $(8-9 \%){ }^{45}$ As we have explained above, the difference between income and consumption responses provides an estimate of the change in the consumption-income gap, which is about $10-11 \%$ according to our full sample estimates (also shown in Table 6).

We find weaker responses of consumption and income for households who are close to the threshold of 50,000 rubles. Specifically, the consumption response is close to zero in the WDID estimates. This magnitude is consistent with weaker incentive to switch to tax compliance (because the tax rate is the same before and after the reform) and negligible windfall gains for these households. For example, the windfall gain for a taxpayer with 50,001 rubles is $\frac{(50,001-50,000) \cdot 8 \%}{50,001} \approx 0.0016 \%$. Hence, consumption for these taxpayers can respond only to productivity changes. Although our WDID estimates of the consumption response have large standard errors and we cannot reject the hypothesis that the productivity effect is either zero or equal to the magnitude we compute below based on the DID estimates, in our view WDID and DID estimates convey the same message that the productivity effect is relatively small when compared with the evasion effect while the windfall gains could be the main factor behind increased consumption.

Using our preferred DID estimates of the treatment effect and our preferred measures of C1 for consumption, Y1 for income, and contractual earnings for the treatment group, we compute the elasticity of the after-tax income response to the change in tax rates: $\in_{Y}=\frac{\partial Y}{\partial t} \times \frac{t}{Y}=$ $\alpha_{Y} \times(t / \partial t)=0.18 \times 0.21 /(-0.08) \approx-0.47$, where $\alpha_{Y}$ is the point estimate of the DID treatment effect in the $\log$ of income function, and the tax rate includes $1 \%$ contributions to the state pension fund. Likewise, we compute the elasticity of consumption response $\epsilon_{C}=\frac{\partial C}{\partial t} \times \frac{t}{C}=\alpha_{C} \times(t / \partial t)=$ $0.08 \times 0.21 /(-0.08) \approx-0.21$, where $\alpha_{C}$ is the point estimate of the DID treatment effect in the log of consumption function.

\footnotetext{
${ }^{45}$ A large increase in household income for the treatment group is consistent with Martinez-Vazquez et al. (2006) finding a significant growth of individual earnings among high earners after the 2001 tax reform.
} 
To estimate the elasticity of total earned income response $\epsilon_{w l}$, we also need the effective tax rate $\kappa$, which falls in the range 0.14 to 0.17 using alternative definitions of income and consumption in our data. We use $\kappa=0.166$ as the benchmark value based on $\mathrm{Y} 1, \mathrm{C} 1$, and contractual earnings for the treatment group in the pre-reform period. The effective tax rate captures the portion of the consumption response that is due to windfall consumption gains as households in the treatment group receive more resources simply by paying lower taxes. As such, the effective tax rate should be removed from the (negative) elasticity of consumption to obtain the elasticity of total earned income with respect to tax rates. Thus, we estimate $\epsilon_{w l} \approx \epsilon_{C}+\kappa=-0.044$ and conclude that the productivity effect measured through $\epsilon_{w l}$ is relatively small compared to both consumption and reported income responses.

\subsection{Welfare Calculations}

We are now ready to put together our theoretical insights and empirical estimates and compute the welfare gains from flat tax reform in Russia. The lower bound on welfare changes due to income taxes is $\epsilon_{W}^{L}=\epsilon_{w l} \approx-0.044$. The upper bound can be computed either from equation (10) as $\in_{W}^{U}=\left(1-\frac{e}{w l}\right) \in_{T I}=\left(1-\frac{e}{w l}\right)\left(\in_{Y}+\frac{t}{1-t}\right)$ or from equation (11) as $\in_{W}^{U}=\frac{Y}{C} \in_{Y}+\kappa$. Given that the incomeconsumption ratio in our data is about two thirds (see Figure 2), the upper bound on welfare changes based on equation (11) is $\epsilon_{W}^{U} \approx-0.149$. An important byproduct of having two consistent formulas for computing welfare changes is that we can calculate (rather than assume) the share of concealed income in total income $\frac{e}{w l}=1-0.149 /(-0.473+0.21 /(1-0.21)) \approx 0.28$, which is a highly plausible magnitude. We can also calculate the elasticity of evasion with respect to tax rates $\epsilon_{E}=0.376$. 
Given the estimates of welfare response with respect to tax rates, we compute the deadweight loss from personal income taxes. An upper bound on the deadweight loss is $D W L_{W}^{U}=-0.5 t \in_{W}^{U} /\left(1-\frac{e}{w l}\right)=-0.5 \times 0.21 \times(-0.149) /(1-0.28) \approx 2.2 \%$ of taxable income or $13.1 \%$ of collected personal income taxes, which is a significant cost. This estimate assumes that tax evasion has only resource cost and, hence, it coincides with the estimate obtained by Feldstein's approach. The lower bound on the deadweight loss, which assumes that evasion has only transfer cost, is $D W L_{W}^{U}=-0.5 t \in_{W}^{L} /\left(1-\frac{e}{w l}\right) \approx 0.6 \%$ of taxable income or $3.9 \%$ of collected personal income taxes, which is only $30 \%$ of the estimate suggested by Feldstein's approach.

To get a plausible point estimate of the DWL in Russia, we need to have an estimate of $\mu$. Although it is difficult to come by a good estimate of $\mu$, one may put a reasonable bound on it. For example, Chetty (2008a) suggests that the resource cost of doing business in cash to underreport taxable income is less than $5 \%$ of the amount evaded, i.e. $g^{\prime}(e) \leq 0.05$, which in our case corresponds to $\mu=0.05 / 0.21 \approx 0.24$. We choose a more conservative value of $\mu=0.5$ and find $\epsilon_{W}=\epsilon_{w l}-\mu \frac{e}{w l} \epsilon_{E}=-0.097$ and $D W L_{W}^{M}=1.4 \%$ of taxable income. This is substantial, yet it is only about $2 / 3$ of the deadweight loss implied by the taxable income elasticity. Using alternative estimates of $\mu<0.5$ will give us even smaller estimates of the deadweight loss. ${ }^{46}$

To further understand the sources of differences in the estimates of welfare gains, we decompose the traditional measure of welfare changes based on taxable income response into contributions of productivity and tax evasion effects (as follows from equations (9) and (10)).

\footnotetext{
${ }^{46}$ Our welfare calculations are based on fixed elasticities for income, consumption and tax evasion responses. In alternative calculations, we allow elasticities to vary with income. In Appendix Table A4, we separately estimate the responses of taxpayers in $21 \%$ and $31 \%$ tax brackets and find that consumption, income and evasion elasticities increase (in absolute value) with income. Using these income-varying elasticities and $\mu=0.5$, we estimate $D W L_{W}^{U}=1.63 \%$ and $D W L_{W}^{M}=1.02 \%$ of taxable income. Similar to our baseline calculations relying on fixed elasticities, DWL based on our approach is at least $30 \%$ smaller than DWL based on taxable income.
} 


$$
\in_{W}^{U}=\left(1-\frac{e}{w l}\right) \in_{T I}=\underset{\begin{array}{c}
\text { productivity } \\
\text { effect }
\end{array}}{\in_{w l}}+\left(-\frac{e}{w l} \in_{E}\right) .
$$

According to our estimates, the productivity effect is $\epsilon_{w l} \approx-0.044$ while the tax evasion effect is $-\frac{e}{w l} \in_{E} \approx-0.105$. This decomposition implies that $2 / 3$ of the taxable income response comes from reduced evasion, thus suggesting that the productivity effect of the Russian flat tax reform was small relative to the evasion effect.

In Feldstein's approach, this decomposition is not important because the marginal return on evasion (equal to the marginal tax rate) is equalized to the marginal resource cost. In this case, reduced evasion releases resources for consumption since a taxpayer spends fewer resources on evasion. In this framework it does not matter whether consumption expands because individuals earn more income or because fewer resources are wasted in evasion activities. In contrast, our approach makes a distinction between productivity and evasion effects because private returns on evasion are not generally equal to social returns on evasion. Specifically, the transfer cost of evasion introduces a wedge between private and social returns. In plausible situations where the transfer cost dominates the resource cost of evasion, it may be only the productivity effect which matters for social welfare. Our lower bound effectively excludes the evasion effect from welfare calculations. In other words, a large component of the income response determined by the evasion effect can considerably influence estimates of welfare gains from tax changes.

Clearly, the traditional approach of using the elasticity of reported taxable income in welfare calculations can significantly overstate the real welfare gains from the tax reform in the presence of transfer cost of tax evasion. As we see from the Russian experience, the deadweight loss due to the personal income tax can be at least $30 \%$ smaller when adjusted for the tax evasion effect. 
Consequently, the burden of personal income tax and the welfare gains from reducing taxes are considerable, yet smaller than thought before. ${ }^{47}$

\section{Conclusions}

The 2001 Russian flat rate income tax reform has often been heralded as a success story and has been credited with large increases in tax revenues and an improved business climate. Although it has been difficult to differentiate between myth and reality with the Russian experience, many other transitional countries have followed suit with flat rate income tax reforms, and an increasing number of countries around the world are considering the adoption of a flat rate income tax. In this paper we focus on the impact of the flat income tax rate on tax evasion, an issue that was, and continues to be, a major problem in Russia as well as in many other transition and developing countries. We argue that the flat tax reform was instrumental in decreasing tax evasion and that, to a certain extent, greater fiscal revenues for Russia in 2001 and several years beyond can be linked to increased voluntary tax compliance and reporting.

Since tax evasion is not directly observable when integral audit programs are lacking, we use indirect techniques to measure the dynamics of tax evasion. Specifically, we use consumptionincome data and economic theory to estimate the effect of the tax reform on tax evasion. The core theoretical argument is that under the permanent income hypothesis consumption should be equal to permanent income. Assuming that consumption expenditures are fully reported, the discrepancy between the log of consumption and the log of income, which we call the consumption-income gap, indicates that households receive unreported income.

With the goal of separating the tax evasion effect of flat rate income tax reform from other factors, we use the difference-in-difference approach and regression-discontinuity-type analysis in

\footnotetext{
${ }^{47}$ The reform can have other benefits. For example, most developing and transitional countries badly need additional tax revenues. Increasing tax rates on those who are not evading will create excess burden losses. Getting these additional revenues from evaders is more equitable and less distortionary.
} 
various specifications. Regardless of the alternative variable definitions and methods used, we find that ceteris paribus the consumption-income gap decreased by about 9 to 12 percent more for households that experienced a reduction in marginal tax rates. That is, the most significant reduction in tax evasion was for taxpayers that experienced the largest decrease in tax rates after the flat rate income tax was introduced. We also analyze the productivity effect of the tax reform and find it to be relatively small when compared to the tax evasion effect. This result is determined by the small increase in consumption (net of windfall gains) for households that faced lower tax rates after the reform.

These results in the paper have several important policy implications. The adoption of a flat rate income tax is not expected to lead to significant increases in the tax revenues because the productivity response is shown to be fairly small. However, if the economy is plagued by ubiquitous tax evasion, as was the case in Russia, then flat rate income tax reform can lead to substantial revenue gains via increases in voluntary compliance. At the same time, given the argument in Chetty (2008a), a strong evasion response suggests that the efficiency gain from the Russian tax reform perhaps is smaller than thought before. Using observable responses of consumption and income to tax changes, we find that the tax-evasion-adjusted deadweight loss from personal income tax is at least $30 \%$ smaller than the loss implied from the standard method based on the response of reported income to tax changes. Thus, although we find tangible efficiency gains from the tax reform, they are not as large as implied by conventional approaches.

The paper also offers several contributions to the public finance literature. First, we provide strong evidence of a positive relationship between (lower) tax rates and (less) tax evasion. Until now, cross-sectional studies in the tax evasion literature had provided ambiguous results. Second, the paper offers a replicable empirical methodology for the estimation of changes in tax evasion and productivity in response to tax reform in other countries provided there are a longitudinal household 
budget survey and significant changes in the tax structure. Third, we develop a feasible framework to assess the deadweight loss from personal income tax in the presence of tax evasion based on the consumption response to tax changes. Since this framework uses only observable data, it can be widely implemented.

\section{References}

Aarbu, Karl, and Thor Thoresen. 2001. "Income Responses to Tax Changes--Evidence from the Norwegian Tax Reform.” National Tax Journal 54 (June): 319-335.

Alexander, Craig, and Jonathan S. Feinstein. 1987. “A Micro Econometric Analysis of Income Tax Evasion.' unpublished manuscript.

Alm, James, Roy Bahl, and Matthew N. Murray. 1990. "Tax Structure and Tax Compliance.” The Review of Economics and Statistics 72 (November): 603-613.

Altonji, Joseph G., Fumio Hayashi, and Laurence J. Kotlikoff. 1997. "Parental Altruism and Inter Vivos Transfers: Theory and Evidence." Journal of Political Economy 105 (December): 1121-1166.

Arellano, Manuel. 1987. "Computing Robust Standard Errors for Within-Groups Estimators." Oxford Bulletin of Economics and Statistics 49 (August): 431-434.

Auten, Gerald, and Robert Carroll. 1999. "The Effect of Income Taxes on Household Income." Review of Economics and Statistics 81 (November): 681-693.

Berger, Mark, Glenn Blomquist, and Klara Sabirianova Peter. 2008. "Compensating Differentials in Emerging Labor and Housing Markets: Estimates of Quality of Life in Russian Cities.” Journal of Urban Economics 63 (January): 25-55.

Blundell, Richard, Martin Browning and Costas Meghir. 1994. "Consumer Demand and the LifeCycle Allocation of Household Expenditures.” Review of Economic Studies 61 (January): 57-80.

Brown, Charles, and James Medoff. 1989. “The Employer Size-Wage Effect.” Journal of Political Economy 97 (October): 1027-1059.

Browning, Martin, and Annamaria Lusardi. 1996. "Household Saving: Micro Theories and Micro Facts." Journal of Economic Literature 34 (December): 1797-1855.

Chetty, Raj. 2008a. "Is the Taxable Income Elasticity Sufficient to Calculate Deadweight Loss? The Implications of Evasion and Avoidance.” Working Papers no. 13844, NBER, Cambridge, MA.

Chetty, Raj. 2008b. "Sufficient Statistics for Welfare Analysis: A Bridge Between Structural and Reduced-Form Methods,” Working Papers no. 14399, NBER, Cambridge, MA.

Clotfelter, Charles. 1983. "Tax Evasion and Tax Rates: An Analysis of Individual Returns." Review of Economics and Statistics 65 (August): 363-373. 
Eissa, Nada, and Jeffrey B. Liebman. 1996. "Labor Supply Response to the Earned Income Tax Credit." Quarterly Journal of Economics 111 (May): 605-637.

Feinstein, Jonathan. 1991. "An Econometric Analysis of Income Tax Evasion and its Detection." RAND Journal of Economics 22 (Spring): 14-35.

Feldman, Naomi, and Joel Slemrod. 2007. "Estimating Tax Noncompliance with Evidence from Unaudited Tax Returns.” Economic Journal 117 (March): 327-352.

Feldstein, Martin. 1995. "The Effect of Marginal Tax Rates on Taxable Income: A Panel Study of the 1986 Tax Reform Act.” Journal of Political Economy 103 (June): 551-572.

Feldstein, Martin. 1999. "Tax Avoidance and the Deadweight Loss of the Income Tax." Review of Economics and Statistics 81 (November): 674-680.

Fisman, Raymond, and Shang-Jin Wei. 2004. "Tax Rates and Tax Evasion: Evidence from "Missing Imports" in China." Journal of Political Economy 112 (April): 471-496.

Gaddy, Clifford G., and William G. Gale. 2005. "Demythologizing the Russian Flat Tax." Tax Notes International, March 14: 983-988.

Gauthier, Bernard, and Mark Gersovitz. 1997. "Revenue Erosion through Exemption and Evasion in Cameroon, 1993." Journal of Public Economics 64 (June): 407-424.

Gorodnichenko, Yuriy, and Klara Sabirianova Peter. 2007. "Public Sector Pay and Corruption: Measuring Bribery from Micro Data." Journal of Public Economics 91 (June): 963-991.

Gorodnichenko, Yuriy, Klara Sabirianova Peter, and Dmitry Stolyarov. 2008a. "A Bumpy Ride along the Kuznets Curve: Consumption and Income Inequality Dynamics in Russia," unpublished paper.

Gorodnichenko, Yuriy, Jorge Martinez-Vazquez, and Klara Sabirianova Peter. 2008b. "Myth and Reality of Flat Tax Reform: Micro Estimates of Tax Evasion Response and Welfare Effects in Russia," Working Paper no. 13719, NBER, Cambridge, MA.

Goskomstat. 2004. Finances in Russia. Moscow: Federal State Statistics Agency, also earlier editions.

Goskomstat. 2006. Russian Statistical Yearbook. Moscow: Federal State Statistics Agency, also earlier editions.

Goskomstat. 2007a. National Accounts of Russia. Moscow: Federal State Statistics Agency, also earlier editions.

Goskomstat. 2007b. Social Situation and Standards of Living of Population in Russia. Moscow: Federal State Statistics Agency, also earlier editions.

Gourinchas, Pierre-Olivier, and Jonathan A. Parker. 2002. "Consumption over the Life Cycle." Econometrica 70 (January): 47-89.

Gruber, Jon, and Emmanuel Saez. 2002. "The Elasticity of Taxable Income: Evidence and Implications." Journal of Public Economics 84 (April): 1-32.

Guariglia, Alessandra and Byung-Yeon Kim. 2003. "Wage Arrears Uncertainty and Precautionary Saving in Russia." Economics of Transition 11 (July): 493-512.

Hall, Robert E. and Alvin Rabushka. 1985. The Flat Tax. Hoover Institution Press. 
Haider, Steven, and Gary Solon. 2006. "Life-Cycle Variation in the Association between Current and Lifetime Earnings.” American Economic Review 96 (September): 1308-1320.

Hubbard, R. Glenn, Jonathan Skinner, and Stephen P. Zeldes. 1995. "Precautionary Saving and Social Insurance.” Journal of Political Economy 103 (April): 360-399.

Imbens, Guido W., and Thomas Lemieux. 2008. "Regression Discontinuity Designs: A Guide to Practice." Journal of Econometrics 142 (February): 615-635.

Internal Reveneu Service (IRS). 2006. "IRS Updates Tax Gap Estimates." U.S. Internal Revenue Service, IR-2006-28, Feb. 14, 2006, http://www.irs.gov/pub/irs-news/tax_gap_figures.pdf.

Ivanova, Anna, Michael Keen, and Alexander Klemm. 2005. "The Russian Flat Tax Reform." Economic Policy 20 (July): 397-444.

Johnson, David S., Jonathan A. Parker, and Nicholas S. Souleles. 2006. "Household expenditure and the income tax rebates of 2001." American Economic Review 96 (December): 15891610.

Kopczuk, Wojciech, and Joseph P. Lupton. 2007. "To Leave or not to Leave: The Distribution of Bequest Motives.” Review of Economic Studies 74 (January): 207-235.

Laitner, John, and F. Thomas Juster. 1996. "New Evidence on Altruism: A Study of TIAA-CREF Retirees." American Economic Review 86 (September): 893-908.

Lyssiotou, Panayiota, Panos Pashardes, and Thanasis Stengos. 2004. "Estimates of the Black Economy Based on Consumer Demand Approaches.” Economic Journal 114 (July): 622640.

Marion, Justin, and Erich Muehlegger. 2008. "Measuring Illegal Activity and the Effect of Regulatory Innovation: Tax Evasion and the Dyeing of Untaxed Diesel." Journal of Political Economy 116 (August): 633-666.

Martinez-Vazquez, Jorge, and Mark Rider, 2005. "Multiple Modes of Tax Evasion: Theory and Evidence," National Tax Journal 58 (1): 51-76.

Martinez-Vazquez, Jorge, Mark Rider, Riatu Qibthiyyah, and Sally Wallace. 2006. "Who Bears the Burden of Taxes on Labor Income in Russia?” Working Paper no. 06/21, AYSPS International Studies Program.

Martinez-Vazquez, Jorge, Mark Rider, and Sally Wallace. 2008. Russia's Tax Reform. Edward Elgar.

Moffitt, Robert, and Mark Wilhelm. 2000. "Taxes and Labor Supply Decisions of the Affluent." in Does Atlas Shrug? The Economic Consequences of Taxing the Rich, J. Slemrod, ed. New York: Russell Sage Foundation.

Owens, Jeffrey. 2007. "The Ups and Downs of Flatter Taxes.” OECD Observer, No. 261.

Pissarides, Christopher, and Guglielmo Weber. 1989. “An Expenditure-Based Estimate of Britain's Black Economy.” Journal of Public Economics 39 (June): 17-32.

Russian Tax Code, Part II, No. 117-FZ of August 5, 2000. English translation: http://www.russiantax-code.com. 
Sabirianova Peter, Klara, Steve Buttrick, and Denvil Duncan. 2007. "Global Reform of Personal Income Taxation, 1981-2005: Evidence from 189 Countries," Working Paper no. 07/21, AYSPS International Studies Program.

Skoufias, Emmanuel. 2003. "Consumption Smoothing in Russia: Evidence from RLMS." Economics of Transition 11 (January): 67-91.

Slemrod, Joel. 1992. "Do Taxes Matter? Lessons from the 1980's.” American Economic Review 82 (May): 250-256.

Slemrod, Joel. 2007. "Cheating Ourselves: The Economics of Tax Evasion.” Journal of Economic Perspectives 21 (Winter): 25-48.

Triest, Robert K. 1998. "Econometric Issues in Estimating the Behavioral Response to Taxation: A Nontechnical Introduction." National Tax Journal 51 (December): 761-772. 
Table 1: Russian Economy Before and After the Tax Reform

\begin{tabular}{|c|c|c|c|c|c|c|c|c|c|c|c|}
\hline & 1995 & 1996 & 1997 & 1998 & 1999 & 2000 & 2001 & 2002 & 2003 & 2004 & 2005 \\
\hline Nominal GDP, bln. & 1585.0 & 2200.2 & 2585.9 & 2741 & 4767 & 7302 & 9041 & 10830.5 & 13243.2 & 16966.4 & 21598.0 \\
\hline real growth, \% & -4.1 & -3.5 & 0.8 & -4.9 & 5.4 & 9.0 & 5.0 & 4.7 & 7.3 & 7.2 & 6.4 \\
\hline Annual CPI, end year & 232.2 & 121.8 & 111.0 & 184.4 & 136.5 & 120.2 & 118.6 & 115.1 & 112.0 & 111.7 & 110.9 \\
\hline Budget deficit (-), bln. & -49.1 & -94.2 & -127.9 & -155 & -44 & 138 & 265 & 97 & 174 & 760 & 1759 \\
\hline Nominal tax revenues, bln. & 353.3 & 464.3 & 593.4 & 524.8 & 891.4 & 1481.9 & 1955.8 & 2331.0 & 2671.9 & 3299.6 & 4627.2 \\
\hline real growth, $\%$ & $\ldots$ & -9.9 & 11.1 & -25.4 & -1.5 & 20.7 & 13.3 & 3.0 & 0.6 & 4.7 & 15.7 \\
\hline Nominal tax revenues & & & & & & & & & & & \\
\hline from PIT, bln. & 36.7 & 56.7 & 75.6 & 72.2 & 117.1 & 174.3 & 255.5 & 357.8 & 455.3 & 574.2 & 706.6 \\
\hline real growth, $\%$ & $\ldots$ & 6.0 & 15.9 & -19.4 & -5.9 & 8.1 & 25.8 & 21.1 & 11.7 & 6.9 & 1.6 \\
\hline$\%$ of tax revenues & 10.4 & 12.2 & 12.7 & 13.8 & 13.1 & 11.8 & 13.1 & 15.3 & 17.0 & 17.4 & 15.3 \\
\hline Top marginal PIT rate & 30 & 35 & 35 & 35 & 45 & 30 & 13 & 13 & 13 & 13 & 13 \\
\hline
\end{tabular}

Notes: All tax revenues are for the consolidated budget and exclude non-budgetary funds. Real growth of GDP and tax revenues is calculated using a GDP deflator. Sources are Goskomstat (2004), Goskomstat (2006), Federal Tax Department website (www.nalog.ru $)$. 
Table 2: Tax Evasion Function, FE

\begin{tabular}{|c|c|c|c|c|}
\hline & $\operatorname{lnC1-\operatorname {ln}Y1}$ & $\operatorname{lnC2-\operatorname {ln}Y1}$ & $\operatorname{lnC1}-\ln Y 2$ & $\ln C 2-\ln Y 2$ \\
\hline \multicolumn{5}{|c|}{ Panel $A$} \\
\hline \multirow[t]{2}{*}{$\mathrm{N}$ of $\mathrm{HH}$ members } & -0.010 & $-0.033 * *$ & 0.018 & -0.005 \\
\hline & $(0.013)$ & $(0.013)$ & $(0.013)$ & $(0.013)$ \\
\hline \multirow[t]{2}{*}{$\mathrm{N}$ of senior $\mathrm{HH}$ members, $60+$} & $-0.210 * * *$ & $-0.200 * * *$ & $-0.180 * * *$ & $-0.169 * * *$ \\
\hline & $(0.022)$ & $(0.022)$ & $(0.022)$ & $(0.022)$ \\
\hline \multirow[t]{2}{*}{$\mathrm{N}$ of children in $\mathrm{HH}, 18-$} & $0.088 * * *$ & $0.076^{* * *}$ & 0.034 & 0.023 \\
\hline & $(0.022)$ & $(0.022)$ & $(0.021)$ & $(0.021)$ \\
\hline \multirow[t]{2}{*}{ Year $=1998$} & -0.026 & -0.025 & -0.026 & -0.025 \\
\hline & $(0.020)$ & $(0.020)$ & $(0.020)$ & $(0.020)$ \\
\hline \multirow[t]{2}{*}{ Year $=2001$} & $-0.142 * * *$ & $-0.139 * * *$ & $-0.140 * * *$ & $-0.137 * * *$ \\
\hline & $(0.017)$ & $(0.017)$ & $(0.018)$ & $(0.018)$ \\
\hline \multirow[t]{2}{*}{ Year $=2002$} & $-0.221 * * *$ & $-0.213 * * *$ & $-0.216^{* * *}$ & $-0.208 * * *$ \\
\hline & $(0.018)$ & $(0.018)$ & $(0.018)$ & $(0.018)$ \\
\hline \multirow[t]{2}{*}{ Year $=2003$} & $-0.208 * * *$ & $-0.203 * * *$ & $-0.217 * * *$ & $-0.213 * * *$ \\
\hline & $(0.018)$ & $(0.018)$ & $(0.018)$ & $(0.018)$ \\
\hline \multirow[t]{2}{*}{ Year $=2004$} & $-0.268 * * *$ & $-0.262 * * *$ & $-0.265 * * *$ & $-0.260 * * *$ \\
\hline & $(0.018)$ & $(0.018)$ & $(0.018)$ & $(0.018)$ \\
\hline \multicolumn{5}{|l|}{ HH head characteristics } \\
\hline \multirow[t]{2}{*}{ Age } & $-0.004 * * *$ & $-0.004 * * *$ & $-0.002 * *$ & $-0.001 *$ \\
\hline & $(0.001)$ & $(0.001)$ & $(0.001)$ & $(0.001)$ \\
\hline \multirow[t]{2}{*}{ Years of schooling } & -0.006 & -0.004 & $-0.007 *$ & -0.005 \\
\hline & $(0.004)$ & $(0.004)$ & $(0.004)$ & $(0.004)$ \\
\hline \multirow[t]{2}{*}{ Married } & $-0.093 * * *$ & $-0.087 * * *$ & $-0.060 * *$ & $-0.053 * *$ \\
\hline & $(0.024)$ & $(0.024)$ & $(0.023)$ & $(0.023)$ \\
\hline \multirow[t]{2}{*}{ Currently works } & $-0.298 * * *$ & $-0.278 * * *$ & $-0.151 * * *$ & $-0.130 * *$ \\
\hline & $(0.055)$ & $(0.054)$ & $(0.052)$ & $(0.052)$ \\
\hline \multirow[t]{2}{*}{ Years of tenure } & $0.003 * *$ & $0.003 * * *$ & $0.002 *$ & $0.002 * *$ \\
\hline & $(0.001)$ & $(0.001)$ & $(0.001)$ & $(0.001)$ \\
\hline \multirow[t]{2}{*}{ Works at enterprise } & $-0.076^{*}$ & $-0.083 *$ & $-0.081 *$ & $-0.089 * *$ \\
\hline & $(0.046)$ & $(0.045)$ & $(0.044)$ & $(0.044)$ \\
\hline \multirow[t]{2}{*}{ Works in private sector } & $-0.105^{* * *}$ & $-0.105^{* * *}$ & $-0.085^{* * *}$ & $-0.084 * * *$ \\
\hline & $(0.021)$ & $(0.021)$ & $(0.021)$ & $(0.021)$ \\
\hline \multirow[t]{2}{*}{ Log (firm size) } & $-0.020 * * *$ & $-0.019 * * *$ & $-0.016^{* * *}$ & $-0.015 * * *$ \\
\hline & $(0.006)$ & $(0.006)$ & $(0.006)$ & $(0.006)$ \\
\hline $\mathrm{N}$ observations (households) & $24129(6135)$ & $24129(6135)$ & $24723(6202)$ & $24723(6202)$ \\
\hline \multirow[t]{2}{*}{$\mathrm{R}^{2}$ overall } & 0.05 & 0.04 & 0.03 & 0.03 \\
\hline & \multicolumn{4}{|c|}{ Panel B } \\
\hline After reform trend $(2001=1)$ & $\begin{array}{l}-0.067 * * * \\
(0.005)\end{array}$ & $\begin{array}{l}-0.066^{* * *} \\
(0.005)\end{array}$ & $\begin{array}{l}-0.066^{* * *} \\
(0.005)\end{array}$ & $\begin{array}{l}-0.065^{* * *} \\
(0.005)\end{array}$ \\
\hline
\end{tabular}

Notes: We report Arellano (1987) robust standard errors in parentheses to control for arbitrary serial correlation; * significant at $10 \% ; * *$ significant at $5 \% ; * * *$ significant at $1 \%$. Omitted categories are the year 2000 and the state sector. All specifications are estimated on the full sample with household fixed effects (FE). HH denotes household. Household head is the person with the largest income. The dependent variable - consumption-income gap - is defined in the text. Besides the after-reform trend, the model estimated in Panel B includes the same set of covariates as in Panel A. Two dummy variables for missing sector and firm size are included but not shown here. $\mathrm{Cl}=$ expenditures on non-durable goods, $\mathrm{C} 2=\mathrm{C} 1+$ transfers, $\mathrm{Y} 1=$ regular income, and $\mathrm{Y} 2=\mathrm{Y} 1+$ irregular payments. The number of observations in specifications with $\ln \mathrm{Y} 2$ is greater than that with $\ln \mathrm{Y} 1$ because the former specifications include the households reporting irregular payments as the only source of their income. 
Table 3: Consumption-Income Gap and Attitudes toward Taxes, 1998 and 2002

\begin{tabular}{|c|c|c|c|c|}
\hline & InC1-InY1 & $\operatorname{lnC2}-\ln Y 1$ & $\operatorname{lnC1-\operatorname {ln}Y2}$ & $\ln C 2-\ln Y 2$ \\
\hline $\begin{array}{l}\text { Evasion perception index } \\
\text { (at the district level. 38 PSUs) }\end{array}$ & $\begin{array}{c}0.244^{* *} \\
(0.119)\end{array}$ & $\begin{array}{l}0.246^{* *} \\
(0.119)\end{array}$ & $\begin{array}{l}0.368 * * * \\
(0.118)\end{array}$ & $\begin{array}{l}0.370 * * * \\
(0.118)\end{array}$ \\
\hline Year $=2002$ & $\begin{array}{l}-0.173 * * * \\
(0.020)\end{array}$ & $\begin{array}{l}-0.162 * * * \\
(0.020)\end{array}$ & $\begin{array}{l}-0.170 * * * \\
(0.020)\end{array}$ & $\begin{array}{l}-0.160^{* * *} \\
(0.020)\end{array}$ \\
\hline $\begin{array}{l}\mathrm{N} \text { observations } \\
\mathrm{R}^{2}\end{array}$ & $\begin{array}{l}7539 \\
0.09\end{array}$ & $\begin{array}{l}7539 \\
0.07\end{array}$ & $\begin{array}{c}7806 \\
0.05\end{array}$ & $\begin{array}{l}7806 \\
0.04\end{array}$ \\
\hline
\end{tabular}

Notes: We report Arellano (1987) robust standard errors in parentheses to control for arbitrary serial correlation; * significant at $10 \%$;* significant at $5 \%$; ** significant at $1 \%$. Household head is the person with the largest income. The dependent variable - consumption-income gap - is defined in the text. The evasion perception index is a district-level measure for the share of individuals who believe that most people don't pay taxes or pay taxes on less than half of their income (mean $=0.529$, std.dev. $=0.089, \min =0.337, \max =0.774$ ). Besides the local evasion perception index, the model includes the same set of covariates as in Table 2. $\mathrm{C} 1=$ expenditures on non-durable goods, $\mathrm{C} 2=\mathrm{C} 1+$ transfers, $\mathrm{Y} 1=$ regular income, and $\mathrm{Y} 2=\mathrm{Y} 1+$ irregular payments. 
Table 4: Tax Enforcement in Russia Before and After the Tax Reform

\begin{tabular}{|c|c|c|c|c|c|}
\hline & 1999 & 2000 & 2001 & 2002 & 2003 \\
\hline \multicolumn{6}{|c|}{ Tax Audits } \\
\hline $\begin{array}{l}\text { Accrued tax revenues from tax audits and } \\
\text { sanctions, bln. Rubles }\end{array}$ & $189^{\mathrm{c}}$ & 283 & 274 & 220.6 & 261 \\
\hline Of which received, bln. rubles & 30.5 & 41.6 & 59.7 & 68.7 & NA \\
\hline Number of on-site audits, thousands & 796 & 690 & 605 & 468.2 & 331.9 \\
\hline $\begin{array}{l}\text { Number of on-site audits of individual } \\
\text { entrepreneurs, thousands }\end{array}$ & $759^{\mathrm{c}}$ & 664 & 415 & 222.9 & 124.1 \\
\hline $\begin{array}{l}\text { Accrued tax revenues from on-site audits, } \\
\text { bln rubles }\end{array}$ & 49.7 & 75 & 68.4 & NA & 47.7 \\
\hline of which received, bln rubles & 20.3 & 21 & 17.8 & NA & NA \\
\hline \multicolumn{6}{|c|}{ Charges for Tax Law Violations } \\
\hline $\begin{array}{l}\text { Administrative charges against enterprise } \\
\text { managers, thousands people }\end{array}$ & 329 & 350 & 312 & 186 & NA \\
\hline $\begin{array}{l}\text { Administrative charges against individual } \\
\text { entrepreneurs, thousands people }\end{array}$ & 480 & 510 & 289 & 96 & NA \\
\hline Total amount of charges, millions rubles & 195 & 247 & 255 & 150 & NA \\
\hline $\begin{array}{l}\text { Number of blocked bank accounts, } \\
\text { thousands }\end{array}$ & 172 & 256 & 344 & 408 & NA \\
\hline $\begin{array}{l}\text { Number of cases sent to the tax police for } \\
\text { further investigation, thousands }\end{array}$ & NA & 14.4 & 17 & 13.4 & 9.5 \\
\hline $\begin{array}{l}\text { Of which number of criminal cases opened, } \\
\text { thousands }\end{array}$ & 1.3 & 3.2 & 4 & 2.6 & 1.1 \\
\hline
\end{tabular}

Source: Federal Tax Department archive (www.nalog.ru); c - calculated from percentage changes reported in 2000. 
Table 5: Tax Evasion Function: Difference-in-Difference Approach, FE

\begin{tabular}{|c|c|c|c|c|}
\hline & 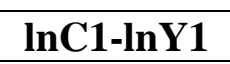 & $\operatorname{lnC2-\operatorname {lnY}1}$ & $\operatorname{lnC} 1-\ln Y 2$ & $\operatorname{lnC} 2-\ln Y 2$ \\
\hline \multirow[t]{2}{*}{$\mathrm{N}$ of HH members } & -0.016 & $-0.037 * * *$ & 0.014 & -0.007 \\
\hline & $(0.014)$ & $(0.014)$ & $(0.014)$ & $(0.014)$ \\
\hline \multirow[t]{2}{*}{$\mathrm{N}$ of senior $\mathrm{HH}$ members, $60+$} & $-0.181 * * *$ & $-0.173 * * *$ & $-0.159 * * *$ & $-0.152 * * *$ \\
\hline & $(0.027)$ & $(0.027)$ & $(0.026)$ & $(0.026)$ \\
\hline \multirow{2}{*}{$\mathrm{N}$ of children in $\mathrm{HH}, 18-$} & $0.087 * * *$ & $0.077 * * *$ & 0.034 & 0.024 \\
\hline & $(0.022)$ & $(0.022)$ & $(0.022)$ & $(0.022)$ \\
\hline \multirow[t]{2}{*}{ Year $=1998$} & -0.020 & -0.016 & -0.028 & -0.025 \\
\hline & $(0.025)$ & $(0.025)$ & $(0.025)$ & $(0.025)$ \\
\hline \multirow[t]{2}{*}{ Year $=2002$} & $-0.073 * * *$ & $-0.068 * * *$ & $-0.072 * * *$ & $-0.066^{* * *}$ \\
\hline & $(0.020)$ & $(0.020)$ & $(0.020)$ & $(0.019)$ \\
\hline \multirow{2}{*}{ Year $=2003$} & $-0.076^{* * *}$ & $-0.073 * * *$ & $-0.080 * * *$ & $-0.077 * * *$ \\
\hline & $(0.020)$ & $(0.020)$ & $(0.019)$ & $(0.019)$ \\
\hline \multirow[t]{2}{*}{ Year $=2004$} & $-0.136^{* * *}$ & $-0.129 * * *$ & $-0.128 * * *$ & $-0.120 * * *$ \\
\hline & $(0.021)$ & $(0.021)$ & $(0.020)$ & $(0.020)$ \\
\hline \multicolumn{5}{|l|}{ HH head characteristics } \\
\hline \multirow[t]{2}{*}{ Age } & $-0.004 * * *$ & $-0.003 * * *$ & $-0.002 * *$ & -0.001 \\
\hline & $(0.001)$ & $(0.001)$ & $(0.001)$ & $(0.001)$ \\
\hline \multirow[t]{2}{*}{ Years of schooling } & -0.007 & -0.006 & $-0.010 * *$ & $-0.009 *$ \\
\hline & $(0.005)$ & $(0.005)$ & $(0.005)$ & $(0.005)$ \\
\hline \multirow[t]{2}{*}{ Married } & $-0.070 * * *$ & $-0.071 * * *$ & -0.031 & -0.030 \\
\hline & $(0.027)$ & $(0.027)$ & $(0.026)$ & $(0.026)$ \\
\hline \multirow[t]{2}{*}{ Currently works } & $-0.293 * * *$ & $-0.277 * * *$ & $-0.158 * * *$ & $-0.142 * * *$ \\
\hline & $(0.055)$ & $(0.055)$ & $(0.052)$ & $(0.051)$ \\
\hline \multirow[t]{2}{*}{ Years of tenure } & $0.002 *$ & $0.002 *$ & 0.001 & 0.002 \\
\hline & $(0.001)$ & $(0.001)$ & $(0.001)$ & $(0.001)$ \\
\hline \multirow[t]{2}{*}{ Works at enterprise } & $-0.083^{*}$ & $-0.084^{*}$ & $-0.081 *$ & $-0.083^{*}$ \\
\hline & $(0.046)$ & $(0.046)$ & $(0.043)$ & $(0.043)$ \\
\hline \multirow[t]{2}{*}{ Works in private sector } & $-0.100 * * *$ & $-0.099 * * *$ & $-0.085 * * *$ & $-0.083 * * *$ \\
\hline & $(0.021)$ & $(0.021)$ & $(0.021)$ & $(0.021)$ \\
\hline \multirow[t]{2}{*}{ Log (firm size) } & $-0.019 * * *$ & $-0.018 * * *$ & $-0.014 * *$ & $-0.013 * *$ \\
\hline & $(0.006)$ & $(0.006)$ & $(0.006)$ & $(0.006)$ \\
\hline \multirow[t]{2}{*}{ After reform dummy $\left(D_{p}\right)$} & $-0.103 * * *$ & $-0.104 * * *$ & $-0.106^{* * *}$ & $-0.107 * * *$ \\
\hline & $(0.031)$ & $(0.031)$ & $(0.031)$ & $(0.031)$ \\
\hline \multirow[t]{2}{*}{$d^{\text {treat }} \times D_{p}$} & $-0.109 * * *$ & $-0.108 * * *$ & $-0.105 * * *$ & $-0.102 * * *$ \\
\hline & $(0.033)$ & $(0.033)$ & $(0.033)$ & $(0.033)$ \\
\hline $\mathrm{N}$ observations (households) & $17081(4174)$ & $17081(4174)$ & $17444(4184)$ & $17444(4184)$ \\
\hline $\mathrm{R}^{2}$ overall & 0.06 & 0.05 & 0.04 & 0.04 \\
\hline
\end{tabular}

Notes: We report Arellano (1987) robust standard errors in parentheses to control for arbitrary serial correlation; * significant at $10 \% ; * *$ significant at $5 \% ; * * *$ significant at $1 \%$. Omitted categories are the state sector and years 2000 and 2001. All specifications are estimated on the full sample with household fixed effects (FE). HH denotes household. Household head is the person with the largest income. The dependent variable - consumption-income gap - is defined in the text. Treatment and control groups are defined on the basis of post-reform unadjusted for inflation earnings received in the last month. The sample includes households whose head is a wage earner (in contrast to Table 2 that is based on the full sample). Two dummy variables for missing sector and firm size are included but not shown here. $\mathrm{C} 1=$ expenditures on non-durable goods, $\mathrm{C} 2=\mathrm{C} 1+$ transfers, $\mathrm{Y} 1=$ regular income, and $\mathrm{Y} 2=\mathrm{Y} 1+$ irregular payments. 
Table 6: Treatment Effect in the Difference-in-Difference Approach

\begin{tabular}{|c|c|c|c|c|}
\hline Alternative Specifications & $\operatorname{lnC1-\operatorname {ln}Y1}$ & $\operatorname{lnC2-\operatorname {ln}Y1}$ & $\operatorname{lnC1-\operatorname {ln}Y2}$ & $\operatorname{lnC2}-\ln \mathrm{Y} 2$ \\
\hline \multicolumn{5}{|c|}{ Panel A. Upper brackets $\times$ after reform dummy $\left(D_{p}=1\right.$ if 2001-2004) } \\
\hline \multicolumn{5}{|c|}{ Contractual earnings } \\
\hline \multirow[t]{3}{*}{ Full sample } & $-0.095 * * *$ & $-0.091 * * *$ & $-0.101 * * *$ & $-0.096 * * *$ \\
\hline & $(0.032)$ & $(0.032)$ & $(0.032)$ & $(0.032)$ \\
\hline & [17287] & [17287] & [17684] & {$[17684]$} \\
\hline \multirow[t]{3}{*}{ Restricted sample in current prices } & $-0.117 * * *$ & $-0.109 * * *$ & $-0.120 * * *$ & $-0.112 * * *$ \\
\hline & $(0.034)$ & $(0.034)$ & $(0.034)$ & $(0.034)$ \\
\hline & [14812] & {$[14812]$} & {$[15123]$} & {$[15123]$} \\
\hline \multirow[t]{3}{*}{ Restricted sample in fixed prices } & $-0.111 * * *$ & $-0.117 * * *$ & $-0.099 * * *$ & $-0.104 * * *$ \\
\hline & $(0.033)$ & $(0.033)$ & $(0.033)$ & $(0.033)$ \\
\hline & [14166] & [14166] & [14455] & {$[14455]$} \\
\hline \multirow{3}{*}{$\begin{array}{l}\text { Restricted sample with } \\
\quad \text { district } \times \text { year interactions }\end{array}$} & $-0.122 * * *$ & $-0.109 * * *$ & $-0.118 * * *$ & $-0.107 * * *$ \\
\hline & $(0.035)$ & $(0.036)$ & $(0.036)$ & $(0.036)$ \\
\hline & [14812] & {$[14812]$} & {$[15123]$} & {$[15123]$} \\
\hline \multirow{3}{*}{$\begin{array}{l}\text { Restricted sample using the } 4 \text {-year } \\
\text { average of contractual earnings }\end{array}$} & $-0.131 * * *$ & $-0.128^{* * *}$ & $-0.145^{* * *}$ & $-0.142 * * *$ \\
\hline & $(0.032)$ & $(0.032)$ & $(0.032)$ & $(0.032)$ \\
\hline & [14812] & [14812] & [15123] & {$[15123]$} \\
\hline \multirow{3}{*}{$\begin{array}{l}\text { Restricted sample without } \\
\text { households with potentially large } \\
\text { deductions }\end{array}$} & $-0.116^{* * *}$ & $-0.109 * * *$ & $-0.123 * * *$ & $-0.117^{* * *}$ \\
\hline & $(0.035)$ & $(0.035)$ & $(0.035)$ & $(0.035)$ \\
\hline & [13322] & [13322] & {$[13615]$} & [13615] \\
\hline \multirow{3}{*}{$\begin{array}{l}\text { Restricted sample without } \\
\text { households with purchases of } \\
\text { declared durables }\end{array}$} & $-0.123 * * *$ & $-0.115 * * *$ & $-0.136 * * *$ & $-0.129 * * *$ \\
\hline & $(0.034)$ & $(0.034)$ & $(0.034)$ & $(0.034)$ \\
\hline & [14522] & {$[14522]$} & [14826] & [14826] \\
\hline \multicolumn{5}{|c|}{ Panel B. Upper brackets $\times$ after reform time trend $\left(t_{p}=1\right.$ if 2001$)$} \\
\hline \multicolumn{5}{|c|}{ Contractual earnings } \\
\hline \multirow[t]{2}{*}{ Full sample } & $-0.033 * * *$ & $-0.031 * * *$ & $-0.034 * * *$ & $-0.032 * * *$ \\
\hline & $(0.010)$ & $(0.010)$ & $(0.010)$ & $(0.010)$ \\
\hline \multirow[t]{2}{*}{ Restricted sample in current prices } & $-0.037 * * *$ & $-0.033 * * *$ & $-0.040 * * *$ & $-0.036 * * *$ \\
\hline & $(0.011)$ & $(0.011)$ & $(0.010)$ & $(0.010)$ \\
\hline \multicolumn{5}{|l|}{ Earnings received last month } \\
\hline \multirow[t]{2}{*}{ Full sample } & $-0.038 * * *$ & $-0.036 * * *$ & $-0.034 * * *$ & $-0.032 * * *$ \\
\hline & $(0.010)$ & $(0.010)$ & $(0.010)$ & $(0.010)$ \\
\hline \multirow[t]{2}{*}{ Restricted sample in current prices } & $-0.036 * * *$ & $-0.034 * * *$ & $-0.039 * * *$ & $-0.037 * * *$ \\
\hline & $(0.011)$ & $(0.011)$ & $(0.011)$ & $(0.011)$ \\
\hline
\end{tabular}

Notes: We report Arellano (1987) robust standard errors in parentheses to correct for arbitrary serial correlation; * significant at $10 \% ; * *$ significant at $5 \% ; * * *$ significant at $1 \%$. The dependent variable - consumption-income gap - is defined in the text. Reported are the estimated coefficients on the interaction term between the treatment group (upper brackets) and a post-reform dummy (or trend in Panel B) using different measures of earnings and samples. All specifications are estimated with household fixed effects and include the same set of variables as in equation (3) and Table 5. The number of observations in panels B is the same as in Panel A. C1=expenditures on non-durable goods, $\mathrm{C} 2=\mathrm{C} 1+$ transfers, $\mathrm{Y} 1=$ regular income, and $\mathrm{Y} 2=\mathrm{Y} 1+$ irregular payments. Households with potentially large deductions are defined as households with recent (2001-2004) purchases of real estate (apartments, houses, dachas, and land) or with expenditures on education in excess of 200 rubles per month, which when annualized amounts to about $10 \%$ of maximum deduction for educational expenditures. Households with purchases of declared durables are those that purchased real estate, vehicles, and stocks that title organizations are required to report to tax authorities after January 1, 2000. Restricted sample includes only households with household head's gross income between 20,000 and 100,000 rubles per year. For incomes in this range, employers pay the same social tax and employees are not eligible for standard deductions. 
Table 7: Treatment Effect in the Difference-in-Difference Approach: Heterogeneous Response

\begin{tabular}{lllll} 
Alternative Specifications & $\ln C 1-\ln Y 1$ & $\ln C 2-\ln Y 1$ & $\ln C 1-\ln Y 2$ & $\ln C 2-\ln Y 2$ \\
\hline
\end{tabular}

State vs. public sector

$\begin{array}{cllll}d^{\text {treat }} \times D_{p}(\text { State sector is omitted }) & 0.001 & -0.017 & -0.014 & -0.030 \\ & (0.054) & (0.054) & (0.052) & (0.052) \\ d^{\text {treat }} \times D_{p} \times \text { Private } & -0.229^{* * *} & -0.192^{* *} & -0.236^{* * *} & -0.201^{* *} \\ & (0.080) & (0.080) & (0.079) & (0.079) \\ \text { N observations } & 17287 & 17287 & 17684 & 17684\end{array}$

Blue collar vs. White collar

$\begin{array}{lllll}d^{\text {treat }} \times D_{p} \times \text { Private } & -0.111 & -0.073 & -0.133 & -0.097 \\ (\text { Blue collar workers are omitted }) & (0.103) & (0.103) & (0.099) & (0.099) \\ d^{\text {treat }} \times D_{p} \times \text { Private } \times \text { White collar } & -0.302^{* *} & -0.308^{* *} & -0.295^{* *} & -0.297^{* *} \\ & (0.123) & (0.125) & (0.124) & (0.124) \\ \text { N observations } & 17287 & 17287 & 17684 & 17684\end{array}$

Notes: We report Arellano (1987) robust standard errors in parentheses to control for arbitrary serial correlation; * significant at $10 \%$; ** significant at $5 \% ; * * *$ significant at $1 \%$. The dependent variable - consumption-income gap - is defined in the text. Reported are the estimated coefficients on the interaction term between the treatment group (upper brackets) and a post-reform dummy using different measures of earnings. Treatment and control group are defined on the basis of post-reform contractual earnings. All specifications are estimated with household fixed effects and include the same set of variables as in equation (3) and Table 4. $\mathrm{C} 1=$ expenditures on non-durable goods, $\mathrm{C} 2=\mathrm{C} 1+$ transfers, $\mathrm{Y} 1=$ regular income, and $\mathrm{Y} 2=\mathrm{Y} 1+$ irregular payments. 
Table 8: Treatment Effect in the Weighted Difference-in-Difference Approach

\begin{tabular}{|c|c|c|c|c|}
\hline Alternative specifications & $\ln C 1-\ln Y 1$ & $\operatorname{lnC2}-\ln Y 1$ & $\ln C 1-\ln Y 2$ & $\operatorname{lnC2}-\ln Y 2$ \\
\hline Earnings received last month & $\begin{array}{l}-0.120 * * \\
(0.050)\end{array}$ & $\begin{array}{l}-0.120^{* *} \\
(0.050)\end{array}$ & $\begin{array}{l}-0.123^{* * *} \\
(0.050)\end{array}$ & $\begin{array}{l}-0.123 * * \\
(0.050)\end{array}$ \\
\hline $\mathrm{N}$ observations (weighted) & 16909 & 16909 & 17261 & 17261 \\
\hline $\mathrm{R}^{2}$ overall & 0.06 & 0.06 & 0.05 & 0.05 \\
\hline Contractual earnings & $\begin{array}{l}-0.098 * * \\
(0.048)\end{array}$ & $\begin{array}{l}-0.095^{* *} \\
(0.048)\end{array}$ & $\begin{array}{l}-0.109 * * \\
(0.047)\end{array}$ & $\begin{array}{l}-0.108 * * \\
(0.046)\end{array}$ \\
\hline $\mathrm{N}$ observations (weighted) & 17180 & 17180 & 17571 & 17571 \\
\hline $\mathrm{R}^{2}$ overall & 0.06 & 0.06 & 0.05 & 0.04 \\
\hline
\end{tabular}

Notes: We report Arellano (1987) robust standard errors in parentheses to correct for arbitrary serial correlation; * significant at $10 \%$; $* *$ significant at $5 \% ; * * *$ significant at $1 \%$. The dependent variable - consumption-income gap is defined in the text. Reported are the estimated coefficients on the interaction term between the treatment group (upper brackets) and a post-reform dummy. All specifications are estimated by weighted least squares with household fixed effects, and include the same set of variables as in equation (3) and Table 4. The WDID approach produces the same estimates for both full and restricted samples because observations beyond the restricted sample have zero weights. $\mathrm{C} 1=$ expenditures on non-durable goods, $\mathrm{C} 2=\mathrm{C} 1+$ transfers, $\mathrm{Y} 1=$ regular income, and $\mathrm{Y} 2=\mathrm{Y} 1+$ irregular payments. 
Table 9: Comparison of Approaches to Assess Welfare Losses from Personal Income Taxes

\begin{tabular}{ll} 
Feldstein & Our approach \\
$(1999)$ & \\
\hline
\end{tabular}

Panel A: Model

Resource cost of evasion

Transfer cost of evasion

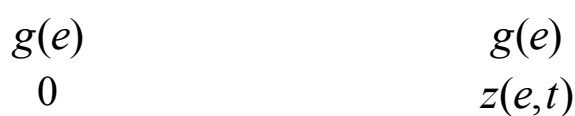

Welfare, $W$

$w l-g(e)-\psi(l) \quad w l-g(e)-\psi(l)$

Elasticity of welfare to tax rate

$\left(1-\frac{e}{w l}\right) \in_{T I} \quad \in_{w l}-\mu \frac{e}{w l} \in_{E} \approx \epsilon_{C}+\kappa-\mu\left(\in_{C}-\frac{Y}{C} \in_{Y}\right)$ scaled by true income,

$\epsilon_{W} \equiv \frac{1}{w l} \frac{\partial W}{\partial t}$

Deadweight loss,

$D W L_{W}=-0.5 t \in_{W} /\left(1-\frac{e}{w l}\right)$,

percent of taxable income

Point estimate, $D W L_{W}^{M}$

$-0.5 t \in_{T I}$

$-0.5 t \in_{W} /\left(1-\frac{e}{w l}\right)$

Lower bound, $D W L_{W}^{L}$

$\times$

$-0.5 t\left(\in_{C}+\kappa\right) /\left(1-\frac{e}{w l}\right)$

Upper bound, $D W L_{W}^{U}$

$\times$

$\frac{-0.5 t\left(\kappa+\frac{Y}{C} \in_{Y}\right)}{\left(1-\frac{e}{w l}\right)}=-0.5 t \in_{T I}$

Panel B: Russian case

Deadweight loss,

$D W L_{W}=-0.5 t \in_{W} /\left(1-\frac{e}{w l}\right)$,

percent of taxable income

Point estimate, $D W L_{W}^{M}$

$2.17 \%$

$1.41 \%$

Lower bound, $D W L_{W}^{L}$

$\times \quad 0.64 \%$

Upper bound, $D W L_{W}^{U}$

$\times$

$2.17 \%$

Note: See Section 7 for details on notation and definitions. 
Table 10: Tax Evasion vs. Productivity Effects

\begin{tabular}{|c|c|c|c|c|}
\hline Alternative specifications & $\operatorname{lnY} 1$ & $\operatorname{lnC1}$ & $\ln Y 2$ & $\operatorname{lnC2}$ \\
\hline \multicolumn{5}{|c|}{ Difference-in-difference } \\
\hline \multirow[t]{2}{*}{ Earnings received last month } & $0.189 * * *$ & $0.080 * * *$ & $0.188 * * *$ & $0.087 * * *$ \\
\hline & $(0.029)$ & $(0.024)$ & $(0.030)$ & $(0.024)$ \\
\hline $\mathrm{N}$ observations & 17081 & 17081 & 17444 & 17444 \\
\hline $\mathrm{R}^{2}$ overall & 0.23 & 0.18 & 0.21 & 0.17 \\
\hline \multirow[t]{2}{*}{ Contractual earnings } & $0.175^{* * *}$ & $0.080 * * *$ & $0.184 * * *$ & $0.088 * * *$ \\
\hline & $(0.028)$ & $(0.023)$ & $(0.029)$ & $(0.023)$ \\
\hline $\mathrm{N}$ observations & 17287 & 17287 & 17684 & 17684 \\
\hline \multirow[t]{2}{*}{$\mathrm{R}^{2}$ overall } & 0.22 & 0.18 & 0.21 & 0.17 \\
\hline & ighted differe & 1-difference & & \\
\hline \multirow[t]{2}{*}{ Earnings received last month } & $0.101 * * *$ & -0.019 & $0.106^{* *}$ & -0.017 \\
\hline & $(0.045)$ & $(0.036)$ & $(0.044)$ & $(0.035)$ \\
\hline $\mathrm{N}$ observations & 16909 & 16909 & 17261 & 17261 \\
\hline $\mathrm{R}^{2}$ overall & 0.25 & 0.20 & 0.24 & 0.19 \\
\hline \multirow[t]{2}{*}{ Contractual earnings } & $0.117 * * *$ & 0.018 & $0.130 * * *$ & 0.022 \\
\hline & $(0.041)$ & $(0.037)$ & $(0.043)$ & $(0.037)$ \\
\hline $\mathrm{N}$ observations & 17180 & 17180 & 17571 & 17571 \\
\hline $\mathrm{R}^{2}$ overall & 0.26 & 0.21 & 0.25 & 0.20 \\
\hline
\end{tabular}

Notes: We report Arellano (1987) robust standard errors in parentheses to correct for arbitrary serial correlation; * significant at $10 \%$; ** significant at $5 \%$; ** significant at $1 \%$. Reported are the estimated coefficients on the interaction term between the treatment group (upper brackets) and a post-reform dummy. All specifications are estimated on the full sample with household fixed effects and include the same set of variables as in equation (3) and Table 4. $\mathrm{C} 1=$ expenditures on non-durable goods, $\mathrm{C} 2=\mathrm{C} 1+$ transfers, $\mathrm{Y} 1=$ regular income, and $\mathrm{Y} 2=\mathrm{Y} 1+$ irregular payments. The estimates are obtained from the two systems of simultaneous equations: a) $\ln Y 1$ and $\operatorname{lnC} 1$ and $b$ ) $\ln \mathrm{Y} 2$ and $\ln \mathrm{C} 2$. 
Figure 1: Marginal Personal Income Tax Rate Before and After the Reform

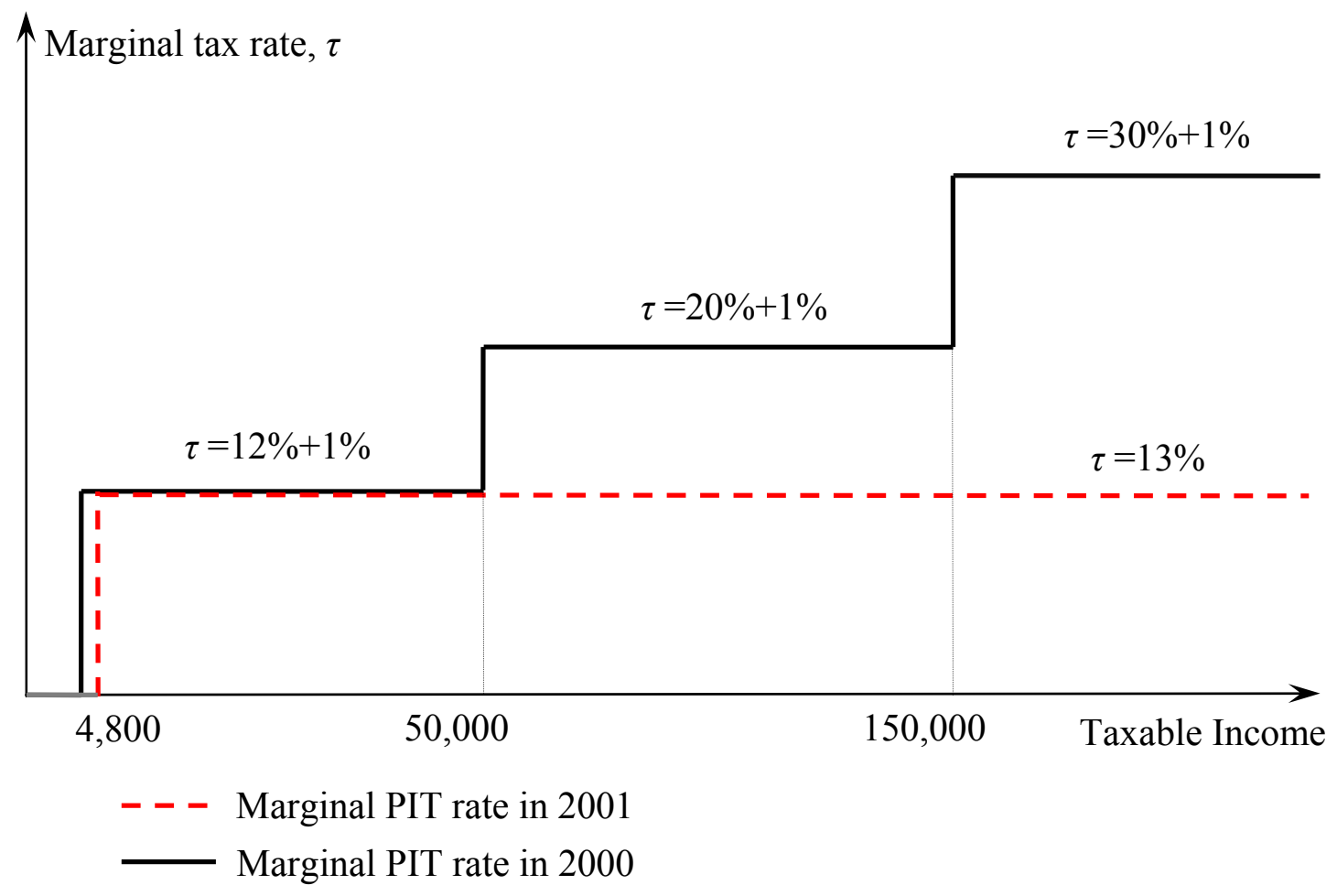

Notes: Taxable income is annual and in rubles. The 2000 marginal PIT rates include 1 percent contribution to the pension fund. Standard deductions were 3,168 rubles in 2000, but they increased to 4,800 rubles in 2001. Standard deductions are applicable only for those with annual income less than 20,000 rubles. 
Figure 2: Comparison of RLMS with Official Statistics
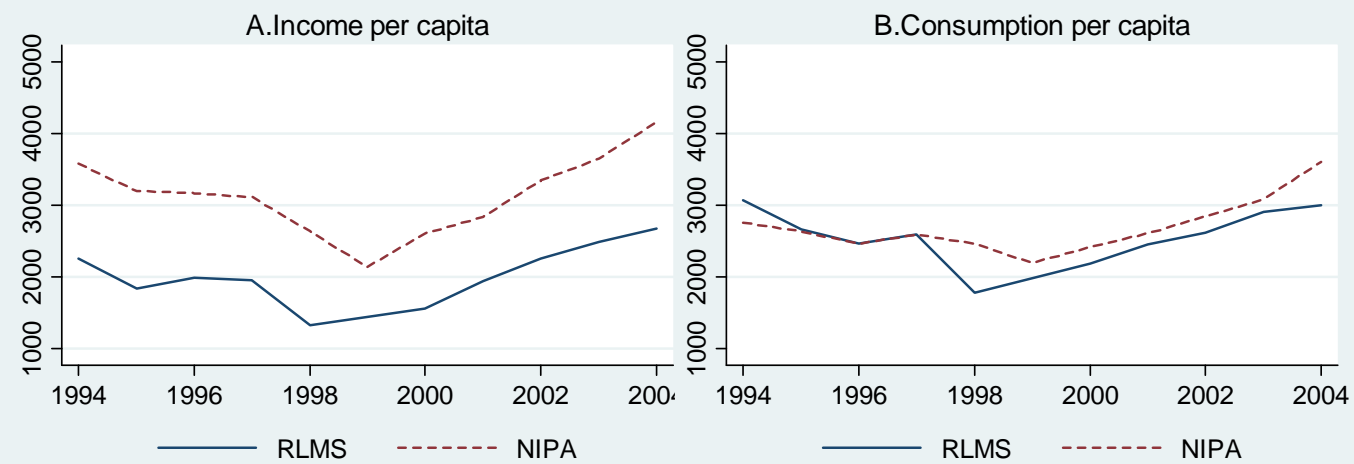

C.Consumption-Income Gap in RLMS
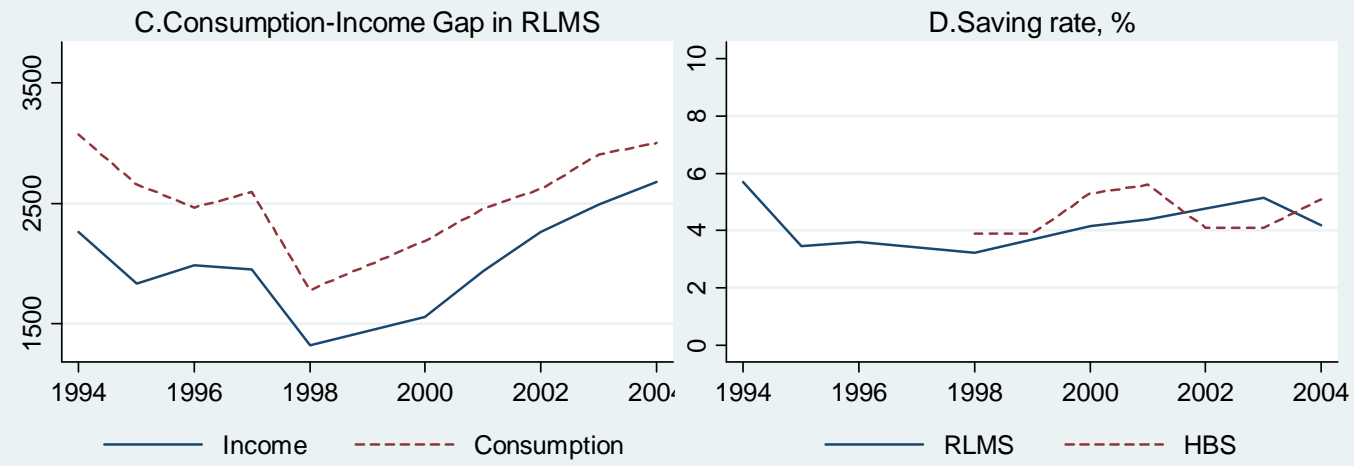

Notes: The RLMS measure of household disposable income per capita is after taxes and transfers given, and it excludes in-kind consumption, such as owner-occupied housing and home-grown food. The matching NIPA measure is disposable income for the "household account" after taxes and transfers minus in-kind consumption (Goskomstat 2007a). Both RLMS and NIPA measures of consumption per capita include expenditures on durables but exclude imputed in-kind expenditures (Goskomstat 2007a). All RLMS measures are deflated using monthly CPI and the date of interview. All NIPA measures are deflated using annual average CPI. RLMS income and consumption for 1997 are imputed using the lagged RLMS value multiplied by the 1997 growth rate from NIPA. The 1998 discrepancy in Panel B can be explained by the fact that RLMS has been conducted right after the August financial crisis while NIPA's numbers are averaged over the year. Official numbers of saving rate are obtained from the Household Budget Survey (Goskomstat 2007b). 
Figure 3: Consumption-Income Gap Dynamics for Treatment and Control Groups

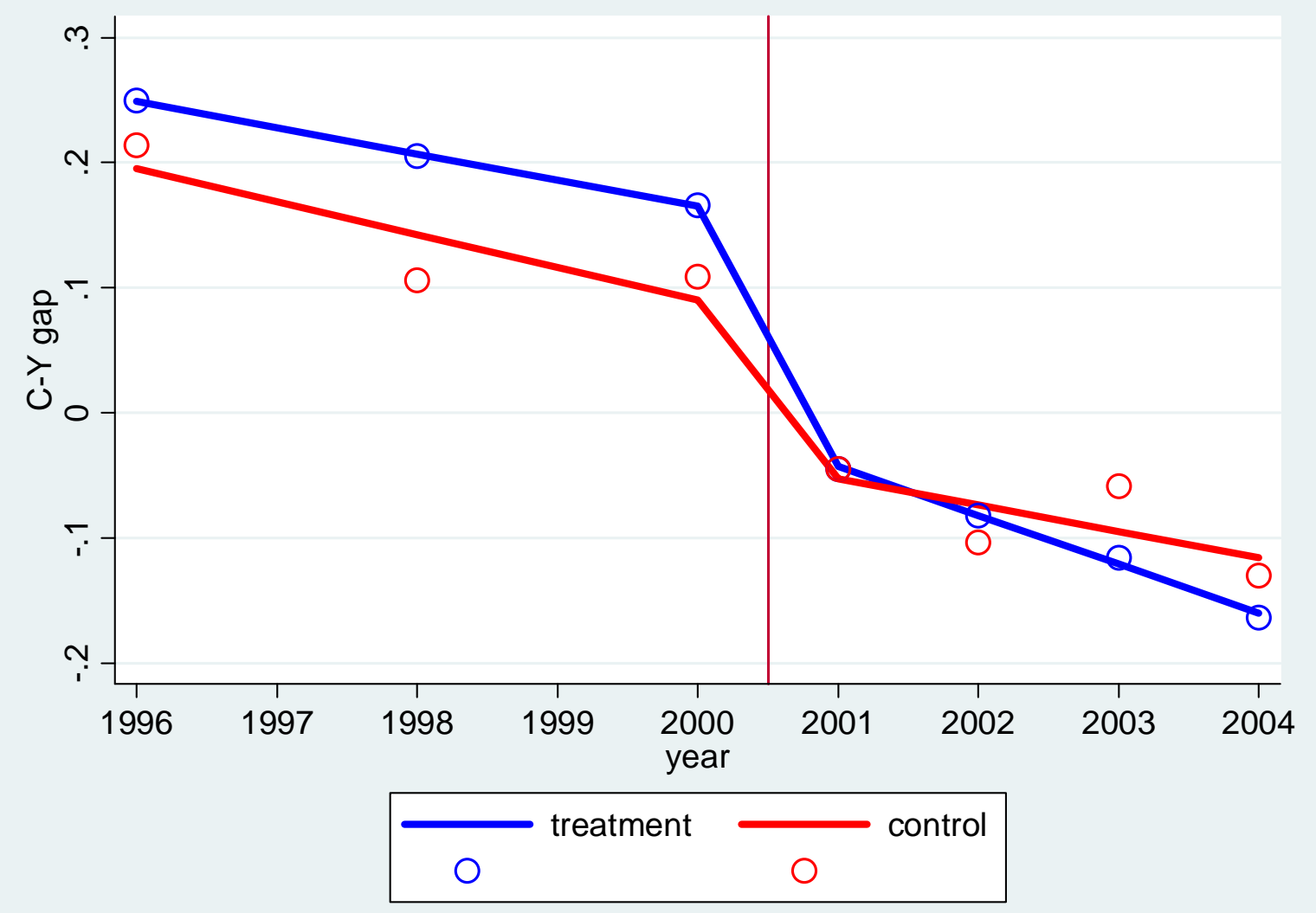

Notes: The figure shows annual means of the consumption-income gap for treatment and control groups after controlling for observable characteristics and household fixed effects. Treatment and control group are defined on the basis of post-reform contractual earnings. 
Figure 4: Income Distribution Below and Above the Threshold
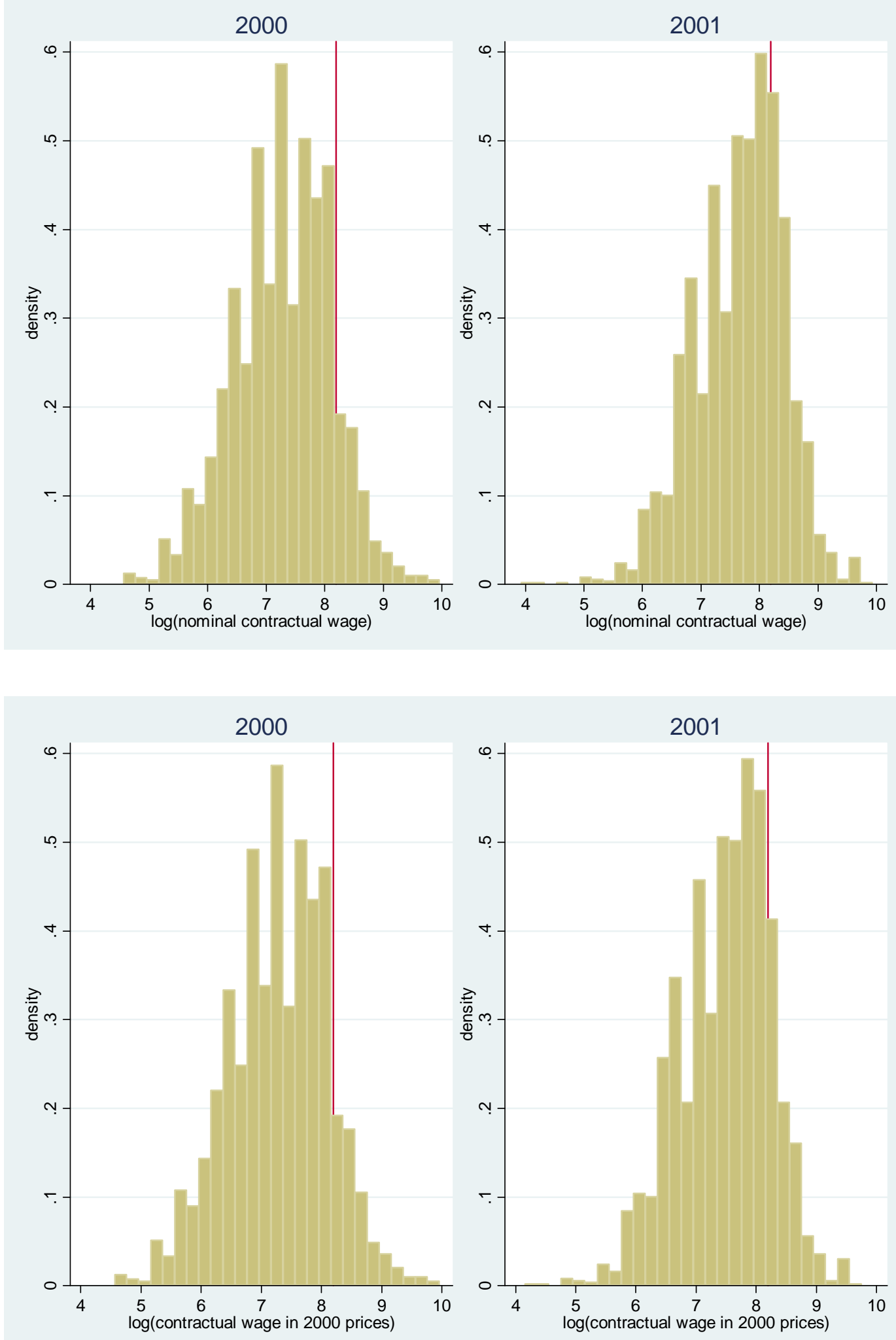

Notes: The histograms display income distribution before and after the 2001 flat tax reform. The vertical line indicates the threshold in the personal income tax. Before the reform (2000), individuals to the left of the line paid $12 \%$ personal income tax rate and $1 \%$ pension fund contributions. Individuals to the right of the line paid 20\% (or $30 \%$ for higher incomes) personal income tax rate and $1 \%$ pension fund contributions. 


\begin{tabular}{|c|c|c|c|}
\hline & All & $\begin{array}{c}\text { Treatment } \\
\text { Group }\end{array}$ & $\begin{array}{l}\text { Control } \\
\text { Group }\end{array}$ \\
\hline $\mathrm{C} 1$ & $\begin{array}{c}6462 \\
(5995)\end{array}$ & $\begin{array}{c}7608 \\
(6675)\end{array}$ & $\begin{array}{c}4331 \\
(3592)\end{array}$ \\
\hline $\mathrm{C} 2$ & $\begin{array}{c}6922 \\
(6743)\end{array}$ & $\begin{array}{c}8135 \\
(7453)\end{array}$ & $\begin{array}{c}4667 \\
(4348)\end{array}$ \\
\hline $\mathrm{C} 3$ & $\begin{array}{c}7816 \\
(11566)\end{array}$ & $\begin{array}{c}9393 \\
(13420)\end{array}$ & $\begin{array}{c}4884 \\
(5863)\end{array}$ \\
\hline $\mathrm{C} 4$ & $\begin{array}{c}5768 \\
(12939)\end{array}$ & $\begin{array}{c}6767 \\
(15336)\end{array}$ & $\begin{array}{c}3909 \\
(6003)\end{array}$ \\
\hline Y1 & $\begin{array}{c}6442 \\
(7134)\end{array}$ & $\begin{array}{c}7880 \\
(7017)\end{array}$ & $\begin{array}{c}3767 \\
(6555)\end{array}$ \\
\hline $\mathrm{Y} 2$ & $\begin{array}{c}7317 \\
(12392)\end{array}$ & $\begin{array}{c}8822 \\
(13005)\end{array}$ & $\begin{array}{c}4517 \\
(10610)\end{array}$ \\
\hline Y3 & $\begin{array}{c}6573 \\
(7242)\end{array}$ & $\begin{array}{c}7973 \\
(7184)\end{array}$ & $\begin{array}{c}3969 \\
(6600)\end{array}$ \\
\hline $\mathrm{N}$ of $\mathrm{HH}$ members & $\begin{array}{c}3.089 \\
(1.322)\end{array}$ & $\begin{array}{c}3.184 \\
(1.286)\end{array}$ & $\begin{array}{c}2.911 \\
(1.370)\end{array}$ \\
\hline $\mathrm{N}$ of senior $\mathrm{HH}$ members, $60+$ & $\begin{array}{c}0.329 \\
(0.609)\end{array}$ & $\begin{array}{c}0.288 \\
(0.575)\end{array}$ & $\begin{array}{c}0.406 \\
(0.661)\end{array}$ \\
\hline $\mathrm{N}$ of children in $\mathrm{HH}, 18-$ & $\begin{array}{c}0.829 \\
(0.862)\end{array}$ & $\begin{array}{c}0.864 \\
(0.845)\end{array}$ & $\begin{array}{c}0.765 \\
(0.889)\end{array}$ \\
\hline Age & $\begin{array}{c}42.229 \\
(14.084)\end{array}$ & $\begin{array}{c}40.622 \\
(12.981)\end{array}$ & $\begin{array}{c}45.219 \\
(15.498)\end{array}$ \\
\hline Years of schooling & $\begin{array}{l}11.869 \\
(2.632)\end{array}$ & $\begin{array}{l}12.234 \\
(2.465)\end{array}$ & $\begin{array}{l}11.190 \\
(2.793)\end{array}$ \\
\hline Married & $\begin{array}{c}0.583 \\
(0.493)\end{array}$ & $\begin{array}{c}0.618 \\
(0.486)\end{array}$ & $\begin{array}{c}0.518 \\
(0.500)\end{array}$ \\
\hline Currently works & $\begin{array}{c}0.833 \\
(0.373)\end{array}$ & $\begin{array}{c}0.884 \\
(0.321) \\
\end{array}$ & $\begin{array}{c}0.740 \\
(0.439) \\
\end{array}$ \\
\hline $\mathrm{N} 1$ & 17046 & 5959 & 11087 \\
\hline Years of tenure & $\begin{array}{c}8.080 \\
(9.376)\end{array}$ & $\begin{array}{c}7.639 \\
(9.006)\end{array}$ & $\begin{array}{c}9.062 \\
(10.082)\end{array}$ \\
\hline Works at enterprise & $\begin{array}{c}0.930 \\
(0.255)\end{array}$ & $\begin{array}{c}0.927 \\
(0.260)\end{array}$ & $\begin{array}{c}0.938 \\
(0.241)\end{array}$ \\
\hline Works in state sector & $\begin{array}{c}0.439 \\
(0.496)\end{array}$ & $\begin{array}{c}0.390 \\
(0.488)\end{array}$ & $\begin{array}{c}0.548 \\
(0.498)\end{array}$ \\
\hline Works in private sector & $\begin{array}{c}0.449 \\
(0.497)\end{array}$ & $\begin{array}{c}0.502 \\
(0.500)\end{array}$ & $\begin{array}{c}0.331 \\
(0.470)\end{array}$ \\
\hline Log (firm size) & $\begin{array}{c}3.357 \\
(2.749)\end{array}$ & $\begin{array}{c}3.473 \\
(2.826)\end{array}$ & $\begin{array}{c}3.098 \\
(2.552)\end{array}$ \\
\hline $\mathrm{N} 2$ & 14203 & 4407 & 9796 \\
\hline
\end{tabular}

Notes: All income and consumption measures are in December 2002 rubles. HH denotes household. Household head is the person with largest earnings. N1 includes the same households as in column 1 of Table 4 whose head was employed at least once after the reform. N2 includes only those households whose head is currently employed in any given year. $\mathrm{C} 1=$ expenditures on non-durable goods, $\mathrm{C} 2=\mathrm{C} 1+$ transfers, $\mathrm{C} 3=\mathrm{C} 1+$ purchases of durables, $\mathrm{C} 4=\mathrm{C} 1+$ net savings, $\mathrm{Y} 1=$ regular income, $\mathrm{Y} 2=\mathrm{Y} 1+$ irregular payments, and $\mathrm{Y} 3=\mathrm{Y} 1+$ income from selling home grown goods. Treatment and control groups are defined on the basis of post-reform contractual earnings. 
Appendix Table A2: Tax Evasion Function with Alternative Measures of Income and Expenditures: Difference-in-Difference Approach, FE

\begin{tabular}{|c|c|c|c|}
\hline & $\begin{array}{c}\operatorname{lnC} 3-\ln Y 1 \text { with } \\
\text { Purchases of Durables }\end{array}$ & $\begin{array}{l}\text { lnC4-lnY1 with } \\
\text { Net Savings }\end{array}$ & $\begin{array}{l}\text { lnC1-lnY3 with } \\
\text { Home Production }\end{array}$ \\
\hline \multirow{2}{*}{$\mathrm{N}$ of $\mathrm{HH}$ members } & -0.002 & $-0.028 *$ & -0.019 \\
\hline & $(0.015)$ & $(0.016)$ & $(0.014)$ \\
\hline \multirow[t]{2}{*}{$\mathrm{N}$ of senior $\mathrm{HH}$ members, $60+$} & $-0.212 * * *$ & $-0.149 * * *$ & $-0.170 * * *$ \\
\hline & $(0.028)$ & $(0.029)$ & $(0.026)$ \\
\hline \multirow[t]{2}{*}{$\mathrm{N}$ of children in $\mathrm{HH}, 18-$} & $0.081 * * *$ & $0.083 * * *$ & $0.088 * * *$ \\
\hline & $(0.023)$ & $(0.025)$ & $(0.022)$ \\
\hline \multirow[t]{2}{*}{ Year $=1998$} & $-0.044 *$ & -0.033 & -0.003 \\
\hline & $(0.026)$ & $(0.027)$ & $(0.025)$ \\
\hline \multirow[t]{2}{*}{ Year $=2002$} & $-0.058 * * *$ & $-0.060 * * *$ & $-0.073 * * *$ \\
\hline & $(0.021)$ & $(0.022)$ & $(0.020)$ \\
\hline \multirow[t]{2}{*}{ Year $=2003$} & $-0.051 * *$ & $-0.040 *$ & $-0.084 * * *$ \\
\hline & $(0.021)$ & $(0.022)$ & $(0.020)$ \\
\hline \multirow[t]{2}{*}{ Year $=2004$} & $-0.107 * * *$ & $-0.106^{* * *}$ & $-0.135 * * *$ \\
\hline & $(0.022)$ & $(0.022)$ & $(0.020)$ \\
\hline \multicolumn{4}{|l|}{ HH head characteristics } \\
\hline \multirow[t]{2}{*}{ Age } & $-0.004 * * *$ & $-0.004 * * *$ & $-0.004 * * *$ \\
\hline & $(0.001)$ & $(0.001)$ & $(0.001)$ \\
\hline \multirow[t]{2}{*}{ Years of schooling } & -0.005 & $-0.010^{*}$ & -0.006 \\
\hline & $(0.005)$ & $(0.005)$ & $(0.005)$ \\
\hline \multirow[t]{2}{*}{ Married } & $-0.067 * *$ & -0.038 & $-0.067 * * *$ \\
\hline & $(0.028)$ & $(0.028)$ & $(0.026)$ \\
\hline \multirow[t]{2}{*}{ Currently works } & $-0.297 * * *$ & $-0.277 * * *$ & $-0.265 * * *$ \\
\hline & $(0.058)$ & $(0.060)$ & $(0.054)$ \\
\hline \multirow[t]{2}{*}{ Years of tenure } & $0.003 * *$ & 0.002 & 0.002 \\
\hline & $(0.001)$ & $(0.001)$ & $(0.001)$ \\
\hline \multirow[t]{2}{*}{ Works at enterprise } & -0.076 & -0.048 & $-0.084^{*}$ \\
\hline & $(0.048)$ & $(0.049)$ & $(0.045)$ \\
\hline \multirow[t]{2}{*}{ Works in private sector } & $-0.093 * * *$ & $-0.068 * * *$ & $-0.099 * * *$ \\
\hline & $(0.023)$ & $(0.023)$ & $(0.021)$ \\
\hline \multirow[t]{2}{*}{$\log$ (firm size) } & $-0.021 * * *$ & $-0.021 * * *$ & $-0.017 * * *$ \\
\hline & $(0.006)$ & $(0.006)$ & $(0.006)$ \\
\hline \multirow[t]{2}{*}{ After reform dummy $\left(D_{p}\right)$} & $-0.110 * * *$ & $-0.098 * * *$ & $-0.085 * * *$ \\
\hline & $(0.032)$ & $(0.033)$ & $(0.030)$ \\
\hline \multirow{2}{*}{ Upper brackets $\times D_{p}$} & $-0.091 * * *$ & $-0.105^{* * *}$ & $-0.114 * * *$ \\
\hline & $(0.034)$ & $(0.035)$ & $(0.032)$ \\
\hline $\mathrm{N}$ observations (households) & $17059(4174)$ & $16373(4152)$ & $17081(4174)$ \\
\hline $\mathrm{R}^{2}$ overall & 0.04 & 0.04 & 0.05 \\
\hline
\end{tabular}

Notes: We report Arellano (1987) robust standard errors in parentheses to correct for arbitrary serial correlation; * significant at $10 \% ; * *$ significant at $5 \% ; * * *$ significant at $1 \%$. Omitted categories are the state sector and years 2000 and 2001. All specifications are estimated on the full sample with household fixed effects (FE). HH denotes household. Household head is the person with the largest income. The dependent variable - consumption-income gap - is defined in the text. Treatment and control groups are defined on the basis of post-reform unadjusted for inflation monthly earnings received in the last month. The sample includes households whose head is a wage earner (in contrast to Table 2 that is based on the full sample). Two dummy variables for missing sector and firm size are included but not shown here. $\mathrm{C} 1=$ expenditures on non-durable goods, $\mathrm{C} 3=\mathrm{C} 1+$ purchases of durables, $\mathrm{C} 4=\mathrm{C} 1+$ net savings, $\mathrm{Y} 1=$ regular income, and $\mathrm{Y} 3=\mathrm{Y} 1+$ income from selling home grown goods. 
Appendix Table A3: Tax Evasion vs. Productivity Effects, Full Specification

\begin{tabular}{|c|c|c|c|c|}
\hline & \multicolumn{2}{|c|}{ Difference-in-Difference } & \multicolumn{2}{|c|}{$\begin{array}{c}\text { Weighted } \\
\text { Difference-in-Difference }\end{array}$} \\
\hline & $\ln Y 1$ & $\operatorname{lnC} 1$ & $\ln Y 1$ & $\ln C 1$ \\
\hline \multirow[t]{2}{*}{$\mathrm{N}$ of $\mathrm{HH}$ members } & $0.214 * * *$ & $0.198 * * *$ & $0.242 * * *$ & $0.204 * * *$ \\
\hline & $(0.013)$ & $(0.011)$ & $(0.017)$ & $(0.015)$ \\
\hline \multirow[t]{2}{*}{$\mathrm{N}$ of senior $\mathrm{HH}$ members, $60+$} & $0.069 * * *$ & $-0.110 * * *$ & $0.045^{*}$ & $-0.121 * * *$ \\
\hline & $(0.024)$ & $(0.020)$ & $(0.028)$ & $(0.029)$ \\
\hline \multirow[t]{2}{*}{$\mathrm{N}$ of children in $\mathrm{HH}, 18-$} & $-0.140 * * *$ & $-0.047 * * *$ & $-0.174 * * *$ & $-0.062 * * *$ \\
\hline & $(0.022)$ & $(0.016)$ & $(0.027)$ & $(0.021)$ \\
\hline \multirow[t]{2}{*}{ Year $=1998$} & $-0.224 * * *$ & $-0.245 * * *$ & $-0.238 * * *$ & $-0.292 * * *$ \\
\hline & $(0.023)$ & $(0.017)$ & $(0.030)$ & $(0.025)$ \\
\hline \multirow[t]{2}{*}{ Year $=2001$} & $0.154 * * *$ & $0.077 * * *$ & $0.130 * * *$ & $0.100 * * *$ \\
\hline & $(0.018)$ & $(0.013)$ & $(0.024)$ & $(0.017)$ \\
\hline \multirow[t]{2}{*}{ Year $=2002$} & $0.239 * * *$ & $0.159 * * *$ & $0.223 * * *$ & $0.167 * * *$ \\
\hline & $(0.019)$ & $(0.013)$ & $(0.024)$ & $(0.018)$ \\
\hline \multirow[t]{2}{*}{ Year $=2003$} & $0.344 * * *$ & $0.203 * * *$ & $0.317 * * *$ & $0.217 * * *$ \\
\hline & $(0.019)$ & $(0.013)$ & $(0.024)$ & $(0.018)$ \\
\hline \multicolumn{5}{|l|}{ HH head characteristics } \\
\hline \multirow[t]{2}{*}{ Age } & $0.002 * *$ & $-0.002 * * *$ & $0.003 * *$ & $-0.002 * *$ \\
\hline & $(0.001)$ & $(0.001)$ & $(0.001)$ & $(0.001)$ \\
\hline \multirow[t]{2}{*}{ Years of schooling } & $0.009 * *$ & 0.002 & 0.009 & 0.005 \\
\hline & $(0.005)$ & $(0.004)$ & $(0.006)$ & $(0.005)$ \\
\hline \multirow[t]{2}{*}{ Married } & $0.182 * * *$ & $0.105^{* * *}$ & $0.158^{* * *}$ & $0.116 * * *$ \\
\hline & $(0.024)$ & $(0.019)$ & $(0.034)$ & $(0.028)$ \\
\hline \multirow[t]{2}{*}{ Currently works } & $0.434 * * *$ & $0.144 * * *$ & $0.447 * * *$ & $0.195 * * *$ \\
\hline & $(0.049)$ & $(0.035)$ & $(0.070)$ & $(0.052)$ \\
\hline \multirow[t]{2}{*}{ Years of tenure } & $-0.002 * *$ & -0.000 & -0.002 & -0.000 \\
\hline & $(0.001)$ & $(0.001)$ & $(0.002)$ & $(0.001)$ \\
\hline \multirow[t]{2}{*}{ Works at enterprise } & 0.054 & -0.031 & $0.115^{* *}$ & -0.021 \\
\hline & $(0.041)$ & $(0.030)$ & $(0.058)$ & $(0.043)$ \\
\hline \multirow[t]{2}{*}{ Works in private sector } & $0.150 * * *$ & $0.055^{* * *}$ & $0.137 * * *$ & 0.028 \\
\hline & $(0.021)$ & $(0.015)$ & $(0.027)$ & $(0.020)$ \\
\hline \multirow[t]{2}{*}{ Log (firm size) } & $0.026^{* * *}$ & $0.007 *$ & $0.023 * * *$ & $0.010^{*}$ \\
\hline & $(0.006)$ & $(0.004)$ & $(0.007)$ & $(0.006)$ \\
\hline \multirow[t]{2}{*}{ After reform dummy $\left(D_{p}\right)$} & $0.153 * * *$ & $0.041 * *$ & $0.172 * * *$ & 0.041 \\
\hline & $(0.026)$ & $(0.020)$ & $(0.039)$ & $(0.033)$ \\
\hline \multirow{2}{*}{ Upper brackets $* D_{p}$} & $0.175 * * *$ & $0.080 * * *$ & $0.117 * * *$ & 0.018 \\
\hline & $(0.028)$ & $(0.023)$ & $(0.041)$ & $(0.037)$ \\
\hline $\mathrm{N}$ observations (households) & 17287 & 17287 & 17180 & 17180 \\
\hline $\mathrm{R}^{2}$ overall & 0.22 & 0.18 & 0.26 & 0.21 \\
\hline
\end{tabular}

Notes: We report Arellano (1987) robust standard errors in parentheses to correct for arbitrary serial correlation; * significant at $10 \%$; $*$ significant at $5 \%$; ** significant at $1 \%$. Omitted categories are the state sector and years 2000 and 2001. All specifications are estimated on the full sample with household fixed effects. $\mathrm{Cl}=$ expenditures on non-durable goods, $\mathrm{C} 2=\mathrm{C} 1+$ transfers, $\mathrm{Y} 1=$ regular income, and $\mathrm{Y} 2=\mathrm{Y} 1+$ irregular payments. The estimates are obtained from the system of two simultaneous equations $\ln Y 1$ and $\operatorname{lnC} 1$. Two dummy variables for missing sector and firm size are included but not shown here. Treatment and control groups are defined on the basis of post-reform contractual earnings. 
Appendix Table A4: Tax Evasion vs. Productivity Effects

\begin{tabular}{|c|c|c|c|c|}
\hline Alternative specifications & $\ln Y 1$ & $\operatorname{lnC1}$ & $\ln \mathrm{Y} 2$ & $\operatorname{lnC2}$ \\
\hline \multicolumn{5}{|c|}{ Earnings received last month } \\
\hline \multirow{2}{*}{ Upper brackets $\times D_{p}$} & $0.139 * * *$ & $0.052 * *$ & $0.136 * * *$ & $0.059 * *$ \\
\hline & $(0.030)$ & $(0.025)$ & $(0.031)$ & $(0.025)$ \\
\hline \multirow{2}{*}{$31 \%$ top bracket $\times D_{p}$} & $0.212 * * *$ & $0.120 * * *$ & $0.225 * * *$ & $0.119 * * *$ \\
\hline & $(0.041)$ & $(0.032)$ & $(0.041)$ & $(0.033)$ \\
\hline $\mathrm{N}$ observations & 17081 & 17081 & 17444 & 17444 \\
\hline $\mathrm{R}^{2}$ overall & 0.23 & 0.18 & 0.21 & 0.17 \\
\hline \multicolumn{5}{|c|}{ Contractual earnings } \\
\hline \multirow[t]{2}{*}{ Upper brackets $\times D_{p}$} & $0.143 * * *$ & $0.062 * * *$ & $0.145^{* * *}$ & $0.065 * * *$ \\
\hline & $(0.029)$ & $(0.024)$ & $(0.030)$ & $(0.024)$ \\
\hline \multirow[t]{2}{*}{$31 \%$ top bracket $\times D_{p}$} & $0.198 * * *$ & $0.091 * *$ & $0.217 * * *$ & $0.093 * *$ \\
\hline & $(0.046)$ & $(0.036)$ & $(0.046)$ & $(0.037)$ \\
\hline $\mathrm{N}$ observations & 17287 & 17287 & 17684 & 17684 \\
\hline $\mathrm{R}^{2}$ overall & 0.23 & 0.18 & 0.21 & 0.17 \\
\hline
\end{tabular}

Notes: We report Arellano (1987) robust standard errors in parentheses to correct for arbitrary serial correlation; * significant at $10 \% ; * *$ significant at $5 \% ; * * *$ significant at $1 \%$. Reported are the estimated coefficients on the interaction of a post-reform dummy with the two upper brackets and the $31 \%$ top bracket. All specifications are estimated on the full sample with household fixed effects and include the same set of variables as in equation (3) and Table 4. $\mathrm{C} 1=$ expenditures on non-durable goods, $\mathrm{C} 2=\mathrm{C} 1+$ transfers, $\mathrm{Y} 1=$ regular income, and $\mathrm{Y} 2=\mathrm{Y} 1+$ irregular payments. The estimates are obtained from the two systems of simultaneous equations: a) $\ln Y 1$ and $\operatorname{lnC} 1$ and $b$ ) $\ln \mathrm{Y} 2$ and $\ln \mathrm{C} 2$. 


\section{Appendix 1: Components of the Russia's 2001 Personal Income Tax Reform}

\section{Main Components of the Reform}

The reform introduced a flat PIT rate of 13 percent; it eliminated the existing progressive rate schedule (with rates of 12 percent up to 50,000 rubles of annual income, 20 percent for 50,001-150,000 rubles, and 30 percent above 150,000 rubles), and 1 percent individual contributions to the pension fund.

The number of deductions was reduced, and the standard deduction was established in the amount of 400 rubles per month for annual income below 20,000 rubles.

All employer contributions to the social security funds (pensions, social insurance and medical insurance) were unified into a social tax. The reform eliminated the contribution to the employment fund and cut the existing flat rate from 38.5 percent, when all contributions were added together, to a regressive scale of 35.6 percent in the bottom bracket, 20 percent for annual worker payroll in excess of 100,000 rubles but less than 300,000 rubles; 10 percent of amounts in excess of 300,000 rubles but less than 600,000 rubles; and 5 percent for amounts in excess of 600,000 rubles. The 5 percent rate was cut to 2 percent on January 1, 2002 . Effective January 1, 2001, the tax code introduced 35 percent tax on income from lotteries, prizes, gambling, large voluntary insurance contributions and excessive interest payments and 30 percent tax on dividends (that is made subject to withholding). The tax on dividends was cut to 6 percent on January 1, 2002.

The reform allowed deductions of charitable contributions up to 25 percent of income; deductions of medical expenses up to 25,000 rubles; deductions of education expenses up to 25,000 rubles; one-time housing deductions for the purchase or construction of a home excluding interest paid on mortgage loans up to 600,000 rubles; and one-time property deductions for the sale of real estate or land plots in the amount that depends on the duration of ownership and the type of the property.

\section{Other Important Changes around the Reform Time}

Part 1 of Tax Code was made effective January 1, 1999. Part 1 replaced the draconian punishment structure by more reasonable penalties for tax-related violations and provided a legal basis for the use of taxpayer identification number but it also limited the enforcement power of the tax authorities.

Effective January 1, 2000, title organizations are required to report to tax authorities the amount individuals spent on purchase of real estate, vehicles, gold, stocks, and valuable art.

In December of 2001 the Government approved the Tax Administration Development Program for 2002-2004. This program included provisions to reform the structure of the tax administration and to develop integrated information systems, among other measures.

\section{Implications for Estimation}

The design of the reforms allows us to identify the treatment and control groups by applying the pre-reform threshold to post-reform income and implement both DID and WDID methods in estimating the behavioral response to policy change.

The WDID estimates around the 50,000 rubles threshold are not affected by deductions. The DID estimates are conducted on the restricted sample that excludes individuals with income below 20,000 rubles.

The WDID estimates around the 50,000 rubles threshold are not affected by the unified social tax. The DID estimates are performed on the restricted sample of workers that are subject to the same social tax rate, with annual income between 20,000 rubles and 100,000 rubles.

Households in our sample do not hold significant financial assets. The average share of capital income and insurance payments in disposable income is $0.6 \%$. The DID and WDID estimates are not sensitive to excluding households with capital income and insurance payments.

Although the number of tax declarations with requested deductions increased rapidly from 821 thousands in 2002 to 1.3 millions in 2004, it is less than 2 percent of individual taxpayers (from Federal Tax Department archive). More than $85 \%$ of all requested deductions in 2002-2004 were for housing purchases and education expenses. The DID and WDID estimates are not sensitive to excluding households with recent purchases of real estate and education expenses.

Various measures of tax enforcement in Table 4 do not indicate significant improvements in the work of tax administration over the sample period. To the extent that the level of tax enforcement efforts is region-specific, we include dummies for 38 local districts (counties) and their interaction with year dummies in the DID specification. The WDID method accounts for changes in tax enforcement by comparing households just below and just above the threshold, with a similar probability of audit. As a robustness check, we exclude households with recent purchases of real estate, vehicles, and stocks. 